\title{
Sterically Encumbered Tetraarylimidazolium Carbenes Pd-PEPPSI Complexes: Highly Efficient Direct Arylation of Imidazoles with Aryl Bromides under Aerobic Conditions
}

Xu-Xian He, ${ }^{\dagger}$ Yinwu Li, ${ }^{*}$ Bei-Bei Ma, ${ }^{\dagger}$ Zhuofeng Ke, ${ }^{*,+}$ and Feng-Shou Liu ${ }^{*,+}$

${ }^{\dagger}$ School of Chemistry and Chemical Engineering, Guangdong Pharmaceutical University, Zhongshan, Guangdong, 528458, China

${ }^{\ddagger}$ MOE Key Laboratory of Bioinorganic and Synthetic Chemistry, School of Materials Science and Engineering, Sun Yat-sen University, Guangzhou 510275, China

Correspondence authors: Zhuofeng Ke, E-mail: kezhf3@mail.sysu.edu.cn; Feng-Shou Liu, E-mail: fengshou2004@126.com.

Content of Supporting Information

1. Crystal structures and optimized structures by DFT calculations

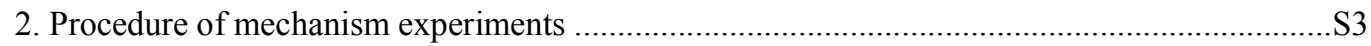

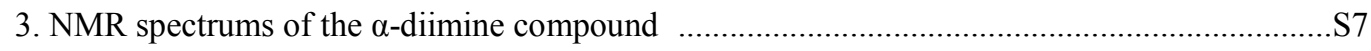

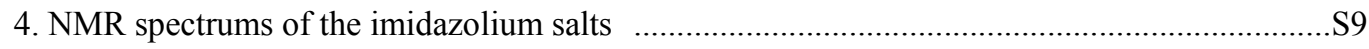

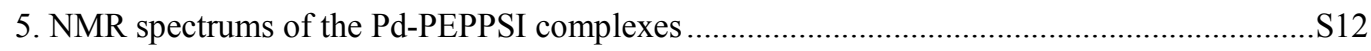

6. NMR spectrums of the arylated cross-coupling products ....................................................... 18 
Table S1. Selected distances $[\AA]$ and angles $\left[^{\circ}\right]$ for the crystal structures and optimized structures of C1, C2 , and GADKIH.
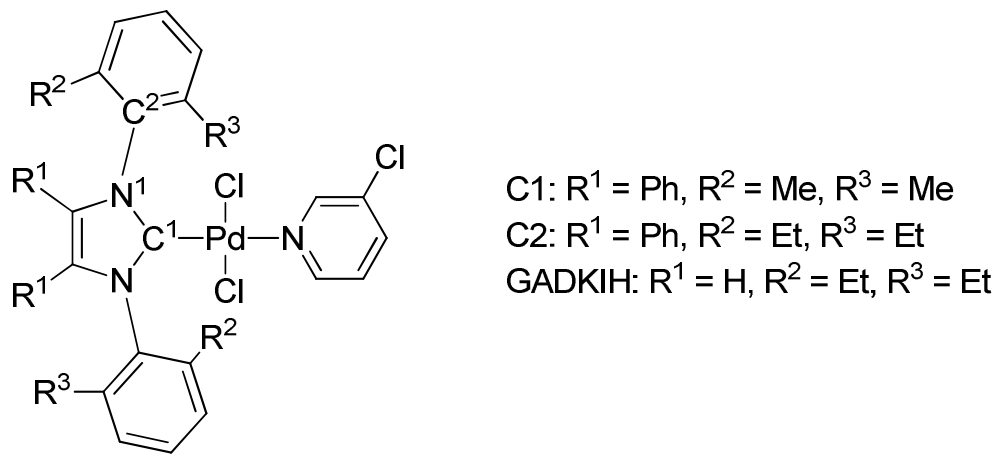

\begin{tabular}{ccc}
\hline $\mathbf{C 1}$ & Crystal structure & DFT Optimized Structure \\
\hline $\mathrm{d}(\mathrm{Pd} 1-\mathrm{C} 29)$ & 1.957 & 1.967 \\
$\angle \mathrm{Pd} 1-\mathrm{C} 29-\mathrm{N} 1$ & 125.0 & 127.0 \\
$\angle \mathrm{C} 29-\mathrm{N} 1-\mathrm{C} 1$ & 123.0 & 123.0 \\
\hline $\mathbf{C} 2$ & & \\
\hline $\mathrm{d}(\mathrm{Pd} 1-\mathrm{C} 16)$ & 1.979 & 1.993 \\
$\angle \mathrm{Pd} 1-\mathrm{C} 16-\mathrm{N} 1$ & 127.2 & 127.3 \\
$\angle \mathrm{C} 29-\mathrm{N} 1-\mathrm{C} 1$ & 124.3 & 124.3 \\
\hline GADKIH & & 1.987 \\
\hline $\mathrm{d}(\mathrm{Pd} 1-\mathrm{C} 16)$ & 1.971 & 127.7 \\
$\angle \mathrm{Pd} 1-\mathrm{C} 16-\mathrm{N} 1$ & 128.4 & 126.9 \\
$\angle \mathrm{C} 29-\mathrm{N} 1-\mathrm{C} 1$ & 126.9 &
\end{tabular}




\section{Procedure of mechanism experiments}

The capture by oxidant experiment was carried out in flask equipped with a

magnetic stirrer. $\quad \mathbf{C 3}(0.01 \mathrm{mmol})$, phenyl bromide $(1.0 \mathrm{mmol})$, 1-methyl-1 $\mathrm{H}$-imidazole $(1.0 \mathrm{mmol}), \mathrm{K}_{2} \mathrm{CO}_{3}(2.0 \mathrm{mmol}), \mathrm{PivOH}(0.3 \mathrm{mmol})$ and $3 \mathrm{~mL}$ of DMAc were added into the reactor. The reaction mixture was carried out at $130{ }^{\circ} \mathrm{C}$ for $12 \mathrm{~h}$ in the presence of $1 \mathrm{~atm}$ of oxygen or 2 equiv of $\mathrm{Cu}(\mathrm{OAc})_{2}$ or 1 equiv of TEMPO. The treatment of the mixture was according to the standard direct arylation.

One-pot competition study on 2-chlorothiophene and 2-methylthiophene with phenyl bromides was performed. C3 $(0.01 \mathrm{mmol})$, phenyl bromide $(1.0 \mathrm{mmol})$, 2-chlorothiophene (1.0 mmol), 2-methylthiophene (1.0 mmol), $\mathrm{K}_{2} \mathrm{CO}_{3}(2.0 \mathrm{mmol})$, PivOH $(0.3 \mathrm{mmol})$ and $3 \mathrm{~mL}$ of DMAc were added to a flask and the reaction was heated to $130{ }^{\circ} \mathrm{C}$ for $7 \mathrm{~min}$. When reaching the setting time, $20 \mathrm{~mL}$ of water was added. The mixture was diluted with $\mathrm{Et}_{2} \mathrm{O}(5 \mathrm{~mL})$, followed by extraction three times $(3 \times 5 \mathrm{~mL})$ with $\mathrm{Et}_{2} \mathrm{O}$ and the added. The resulting mixture was analyzed by GC-MS with the (trifluoromethyl)benzene as internal standard.

\section{Mechanism discussion}

We were then interested to gain some insights into the possible mechanism. The direct reaction between 1-methyl-1H-imidazole (7a) and 1-bromo-4-chlorobenzene (8a) in the presence of 1 equiv of 2,2,6,6-tetramethylpiperidine 1-oxyl (TEMPO) as radical scavenger was performed. The GC yields of 9 aa were obtained in $86 \%$, which 
ruled out the possibility of radical process in the arylation. ${ }^{\mathrm{S} 1}$ The Heck-type mechanism seems like impossible, because its involving of insertion and $\beta-\mathrm{H}$ elimination pathway would favor the generation of $\mathrm{C} 4$-arylation product. $^{\mathrm{S} 2}$ On the other hand, the reaction was carried out in the presence of $1 \mathrm{~atm}$ of oxygen as oxidant, which delivered a much less efficiency of $19 \%$ GC yield. Moreover, none arylated product was found when strong oxidant of $\mathrm{Cu}(\mathrm{OAc})_{2}$ was used. These results suggest the $\operatorname{Pd}(0)$ would be captured by the strong oxidant, which impeded the arylation reaction.

To provide additional evidence for this process or not, a one-pot competition experiment performed with an equimolar mixture of 2-chlorothiophene and 2-methylthiophene was conducted. The experiment showed that arylation of the more electron deficient 2-chlorothiophene was favored over the more nucleophilic 2-methylthiophene in a 4.4:1 ratio (Scheme S1). This outcome excludes a competitive $\mathrm{S}_{\mathrm{E}} \mathrm{Ar}$ pathway ${ }^{3}$ but supported the CMD mechanism for which arylation of the electron deficient substrate was favored. ${ }^{\text {S3 }}$

Scheme S1. One-Pot Competition Study

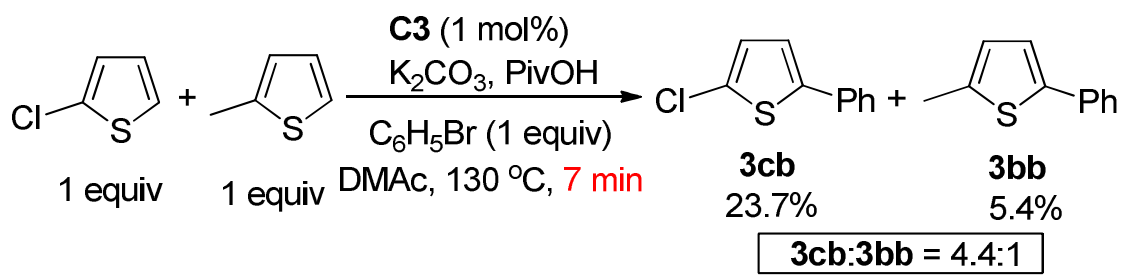

Considered the result obtained above as well as the indispensable role of the PivOH for the cross-coupling reaction, a concerted metalation deprotonation (CMD) 
pathway would occur in the catalytic process(Scheme S2), which is in accordance with the Pd-catalyzed $\mathrm{C}-\mathrm{H}$ functionalization arylation by Fagnou and our previous investigations. $^{\mathrm{S} 4, \mathrm{~S} 5}$

Scheme S2. Proposed Catalytic Cycle for Pd-PEPPSI Catalyzed Direct Arylation of Imidazoles with Aryl Bromides

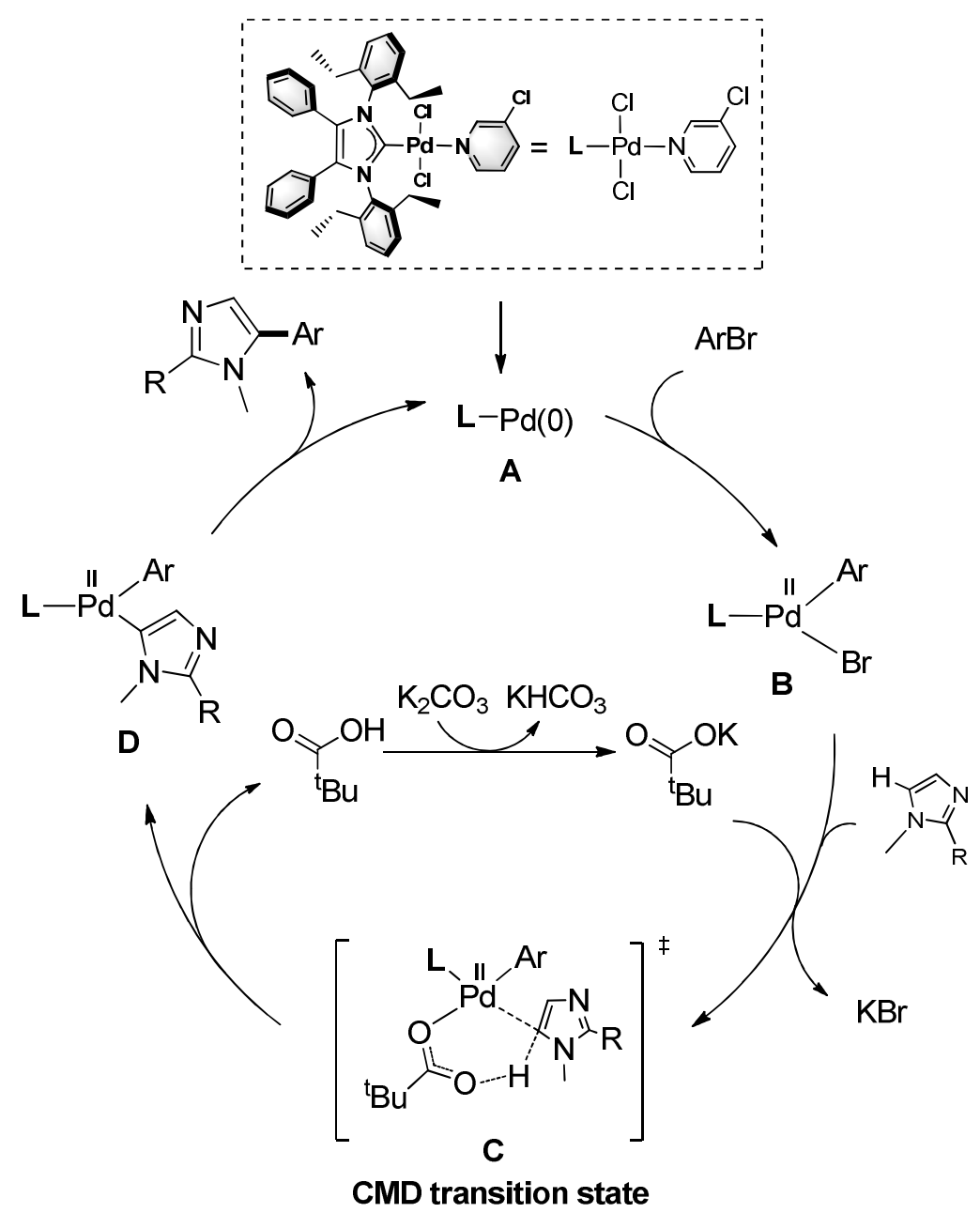

\section{REFERENCES}

(S1) Neufeldta, S. R.; Sanford, M. S. Adv. Synth. Catal. 2012, 354, 3517-3522.

(S2) Kirchberg, S.; Kirika, S. T.; Udea, K.; Yamaguchi, J.; Studer, A. Itami, K. Angew. 
Chem. Int. Ed. 2011, 50, 2387-2391.

(S3) (a) Pivsa-Art, S.; Satoh, T.; Kawamura, Y.; Miura, M.; Nomura, M. Bull. Chem. Soc. Jpn. 1998, 71, 467-473. (b) Sezen, B.; Sames, D. J. Am. Chem. Soc. 2003, 125, 5274-5275. (c) Li, W.; Nelson, D. P.; Jensen, M. S.; Hoerrner, R. S.; Javadi, G. J.; Cai, D.; Larsen, R. D. Org. Lett. 2003, 5, 4835-4837. (d) Park, C.-H.; Ryabova, V.; Sergin, I.V.; Sromek, A. W.; Gevorgyan, V. Org. Lett. 2004, 6, 1159-1162. (e) Lane, B. S.; Brown, M. A.; Sames, D. J. Am. Chem. Soc. 2005, $127,8050-8057$.

(S4) Gorelsky, S. I.; Lapointe, D.; Fagnou, K. J. Org. Chem. 2012, 77, 658-668.

(S5) Luo, B.-T.; Liu, H.; Lin, Z.-J.; Jiang, J.; Shen, D.-S.; Liu, R.-Z.; Ke, Z.; Liu, F.-S. Organometallics 2015, 34, 4881-4894. 
Figure S1. The NMR spectrums of the $\alpha$-diimine compound of $\mathbf{1}$.
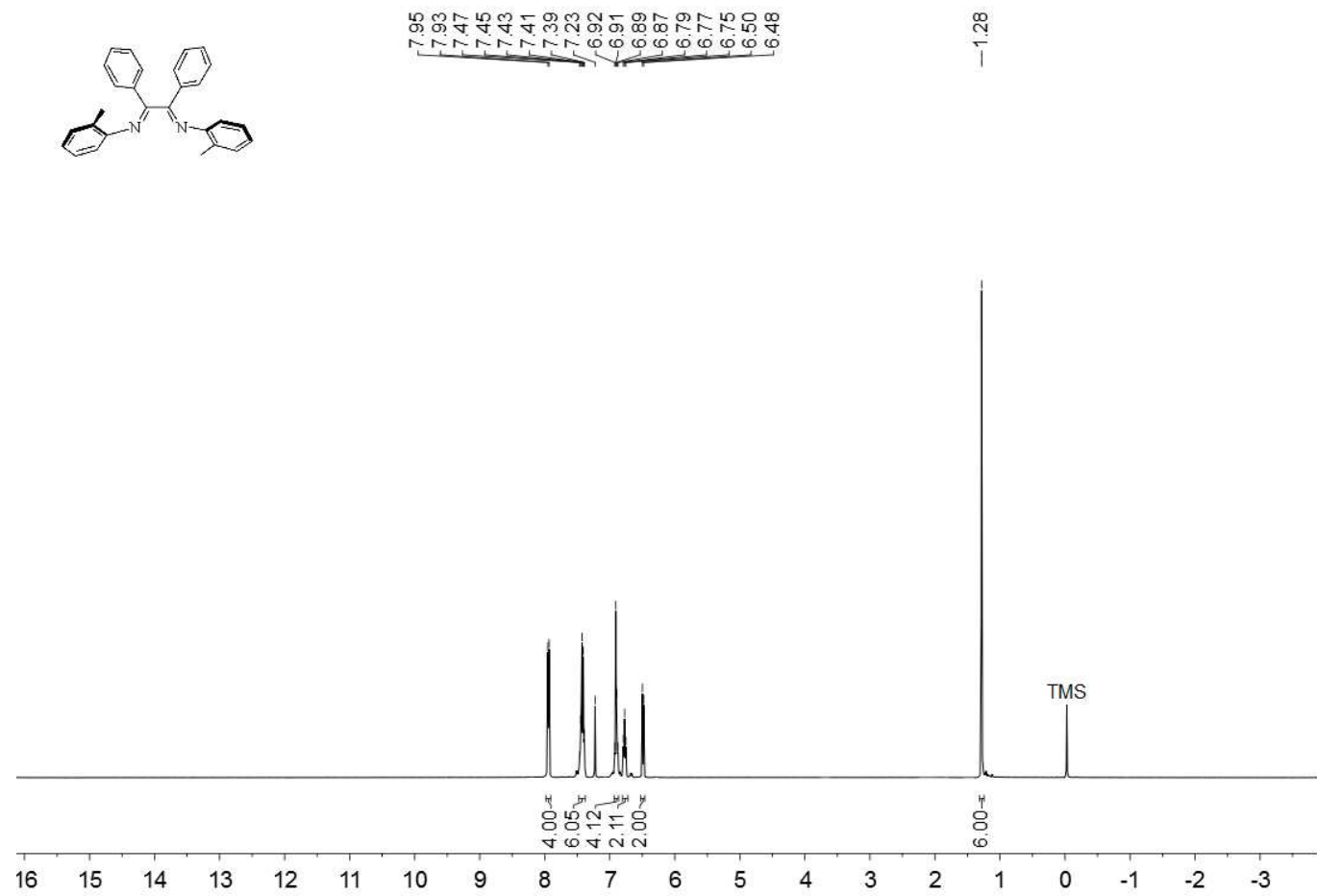

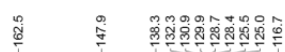
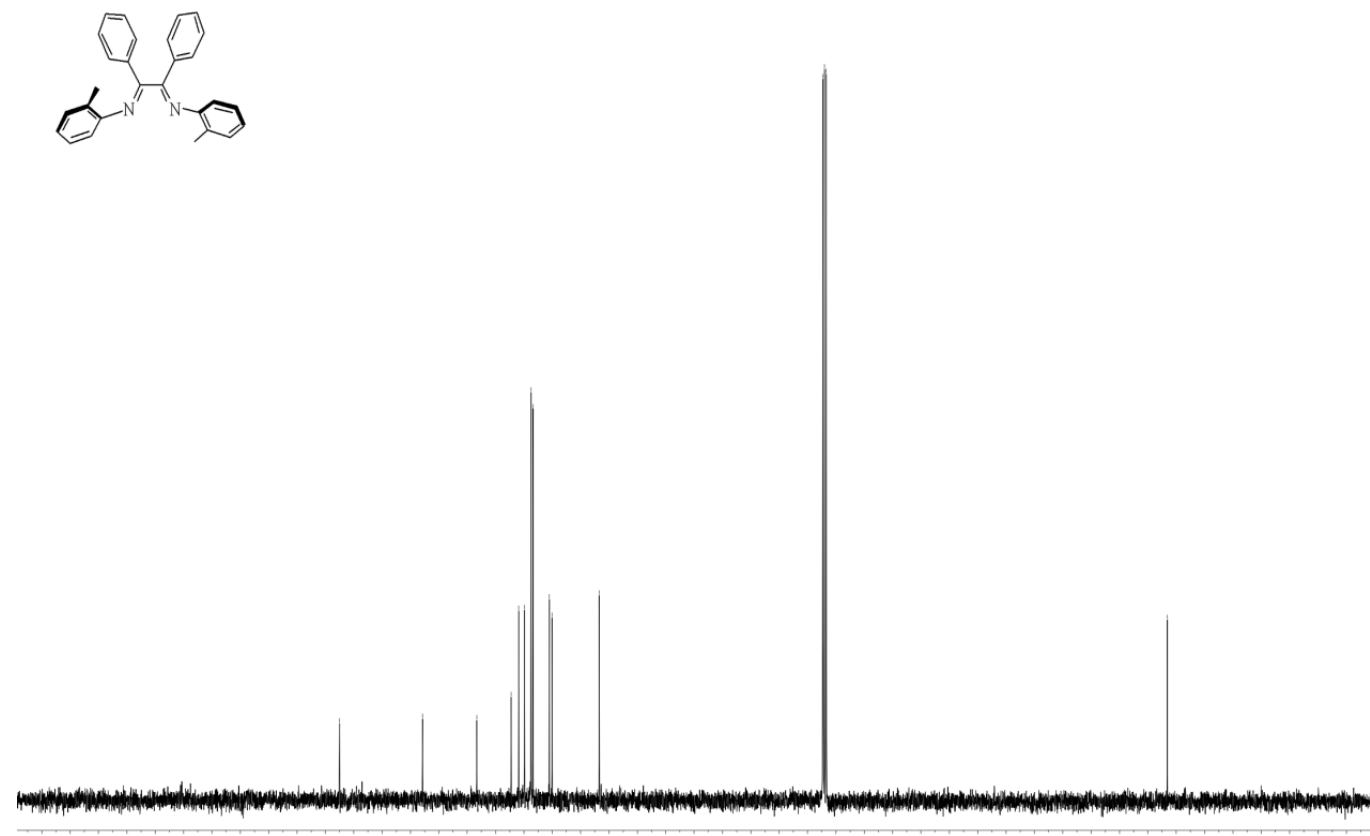

190

110

75

25 
Figure S2. The NMR spectrums of the $\alpha$-diimine compound of $\mathbf{3}$.
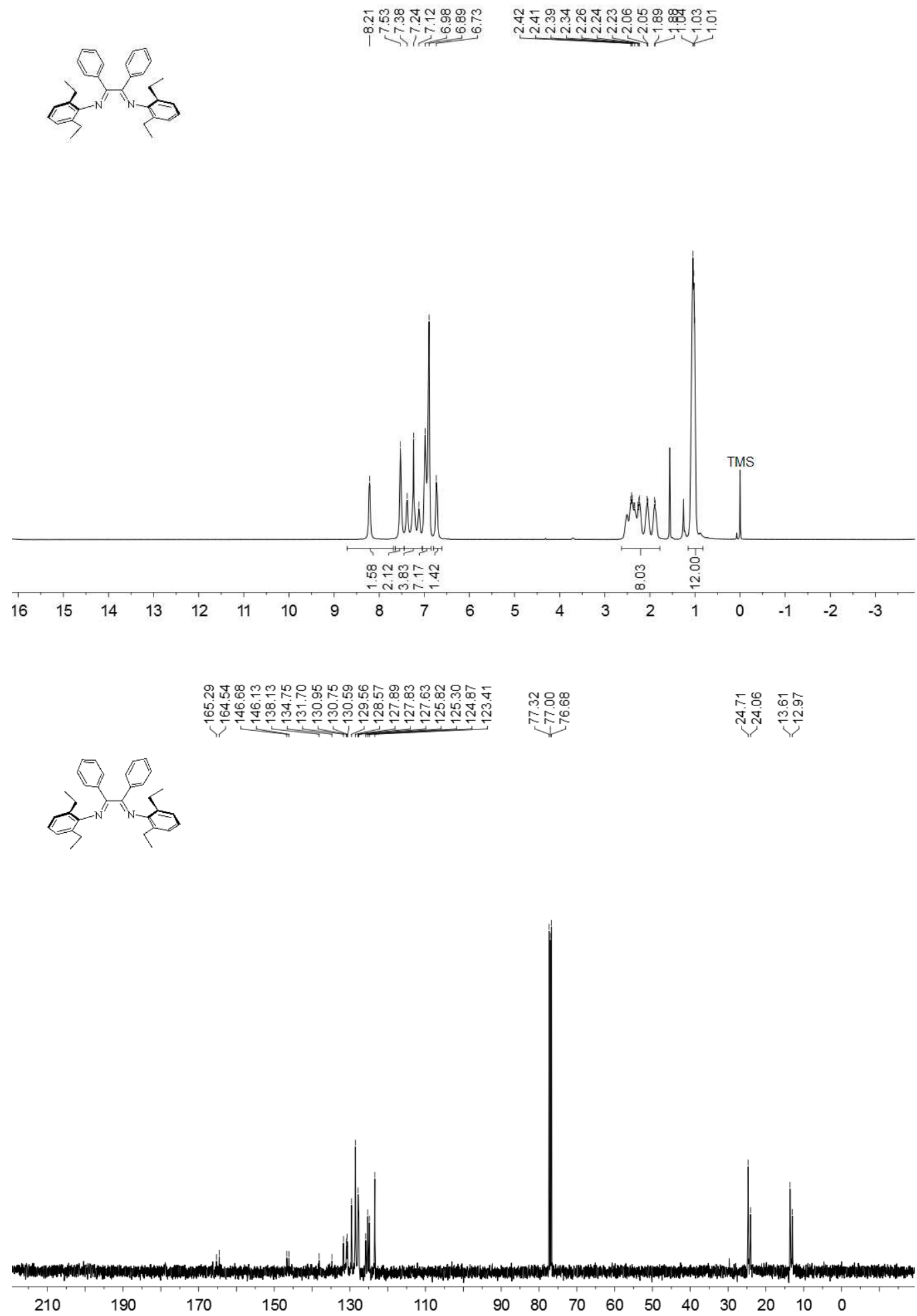
Figure S3. The NMR spectrum of the imidazolium salts compound of L1.
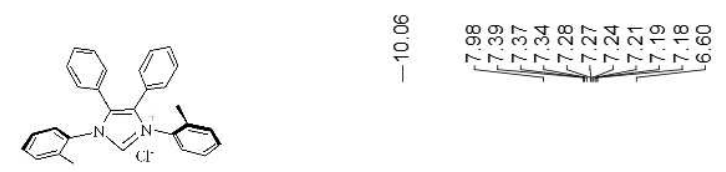

$\stackrel{\circ}{i}$
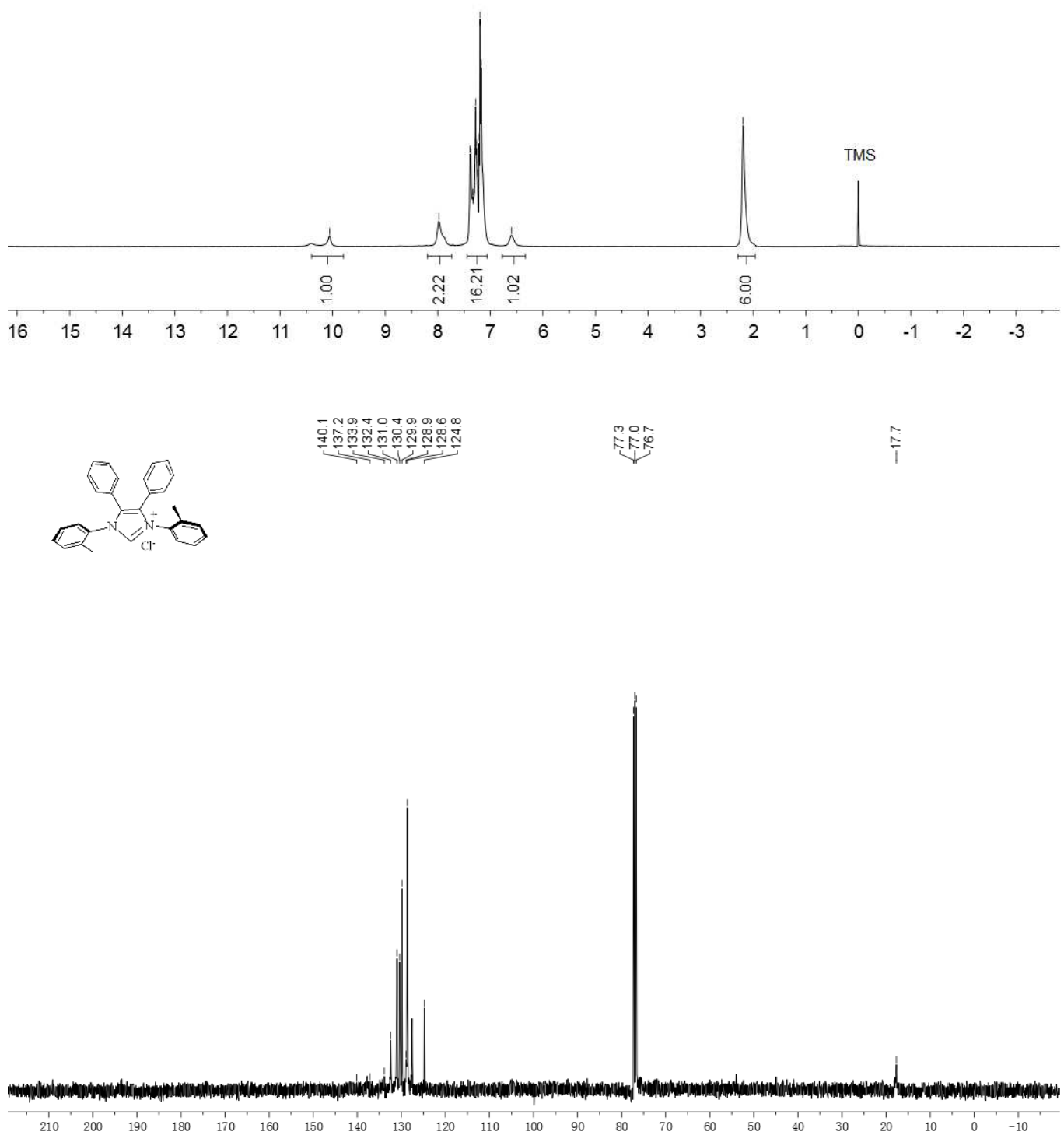

sq 
Figure S4. The NMR spectrums of the imidazolium salts compound of $\mathbf{L 2}$.
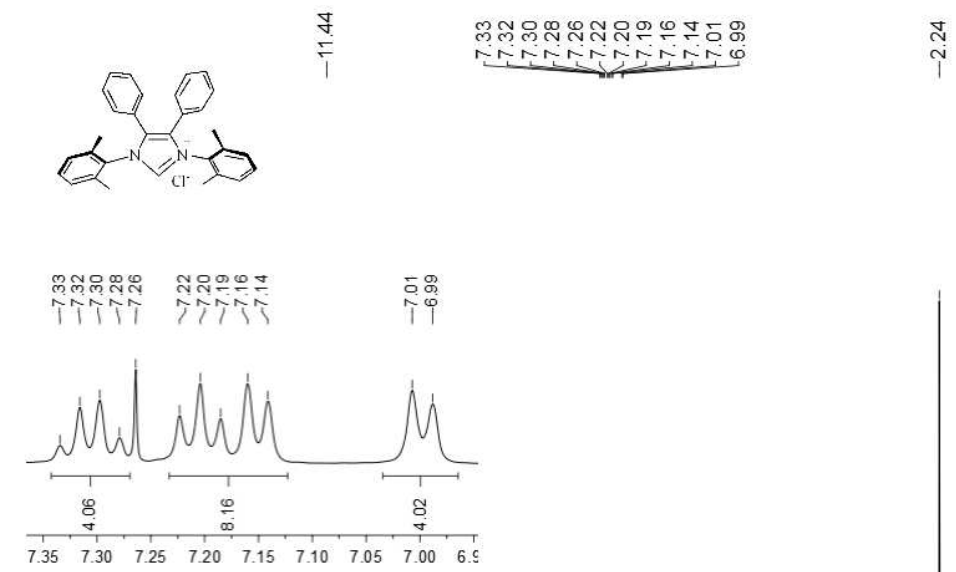

$\underset{N}{\mathbb{1}}$
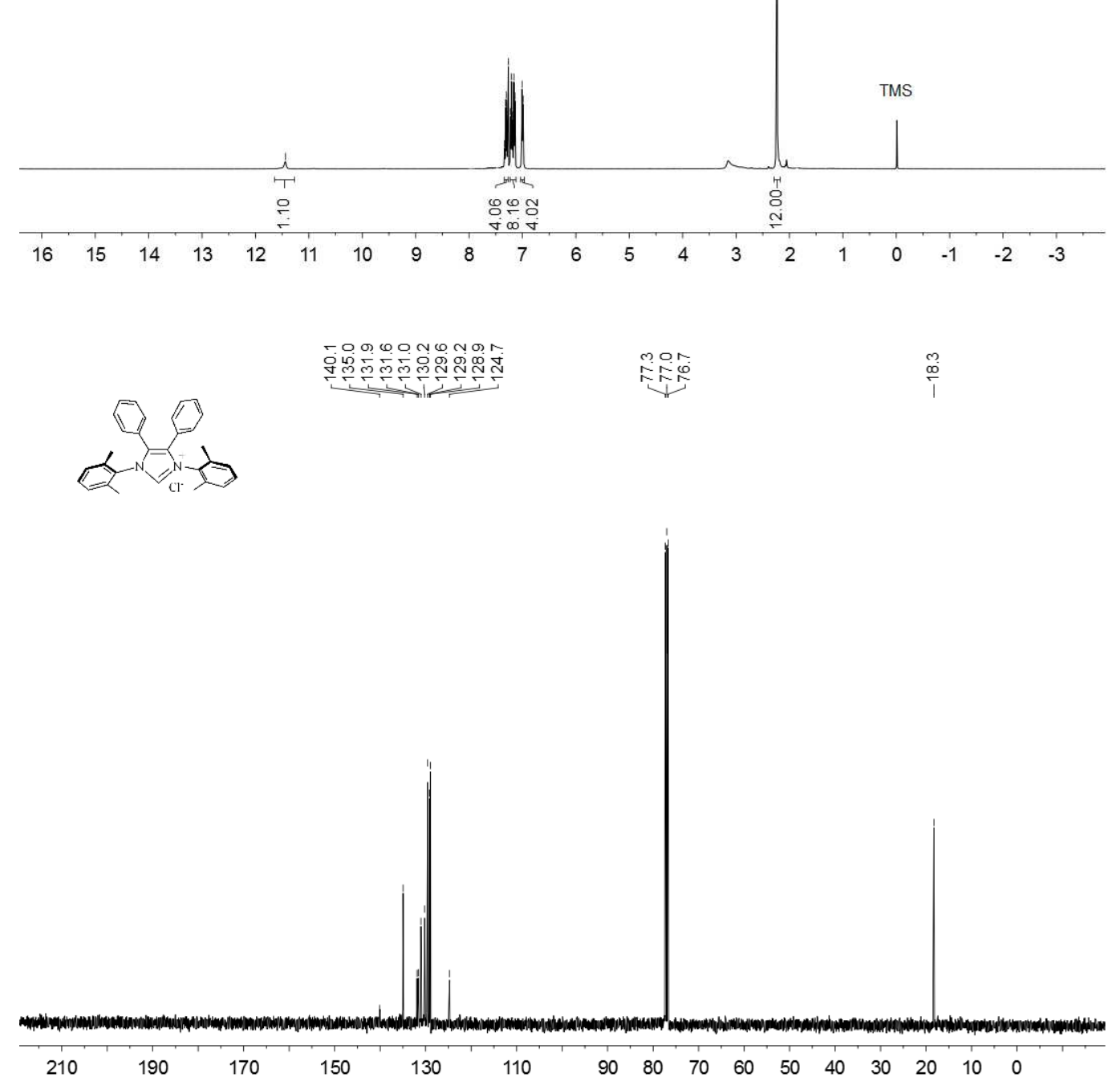
Figure S5. The NMR spectrums of the imidazolium salts compound of $\mathbf{L 3}$.
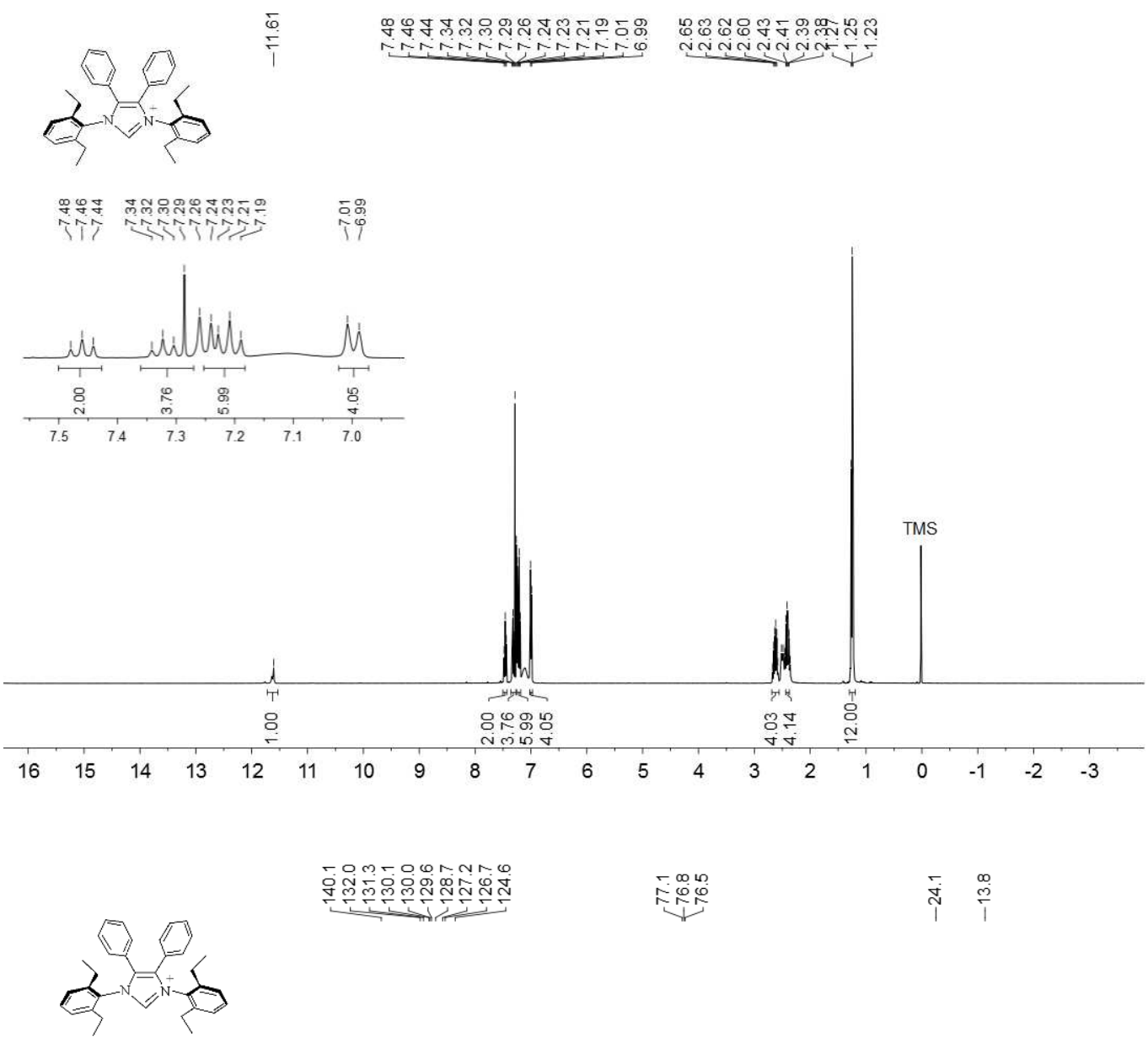

$\stackrel{\leftarrow}{i} \stackrel{\infty}{\Gamma}$

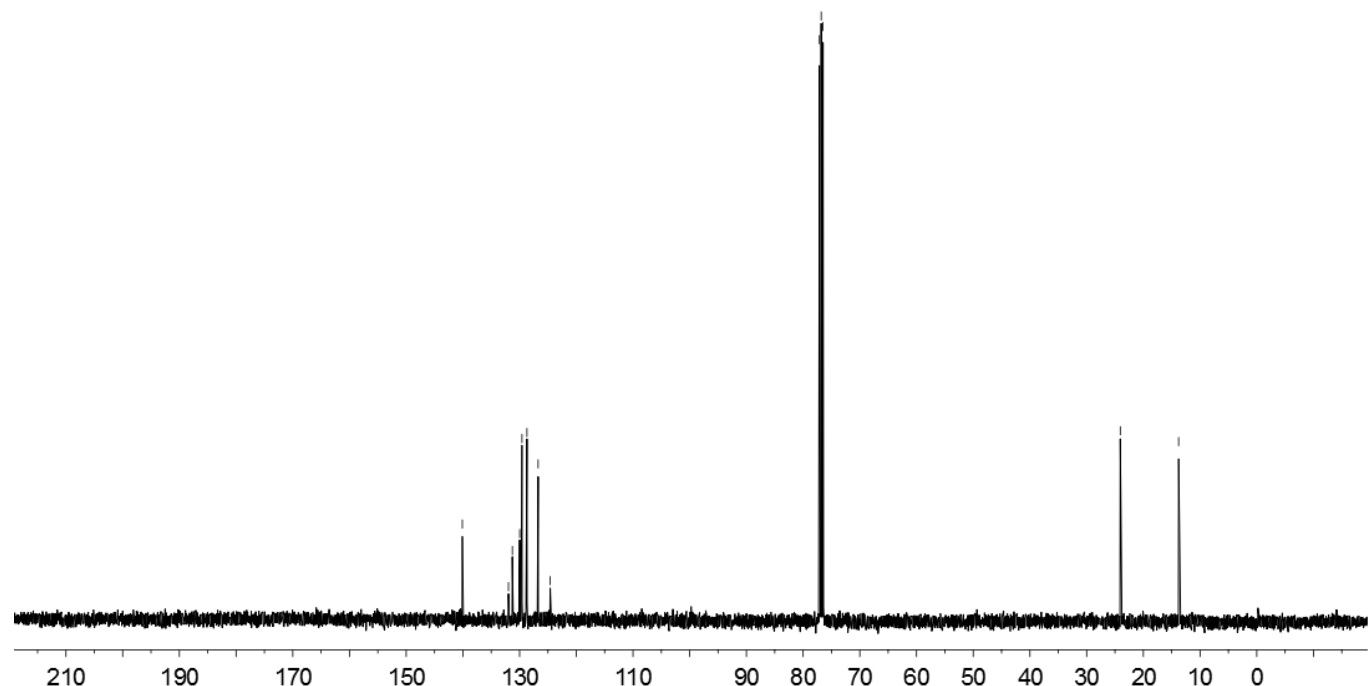


Figure S6. The NMR spectrums of the Pd-PEPPSI complex of C1.

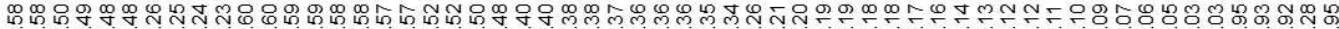

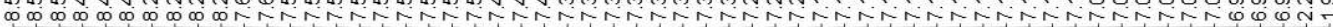
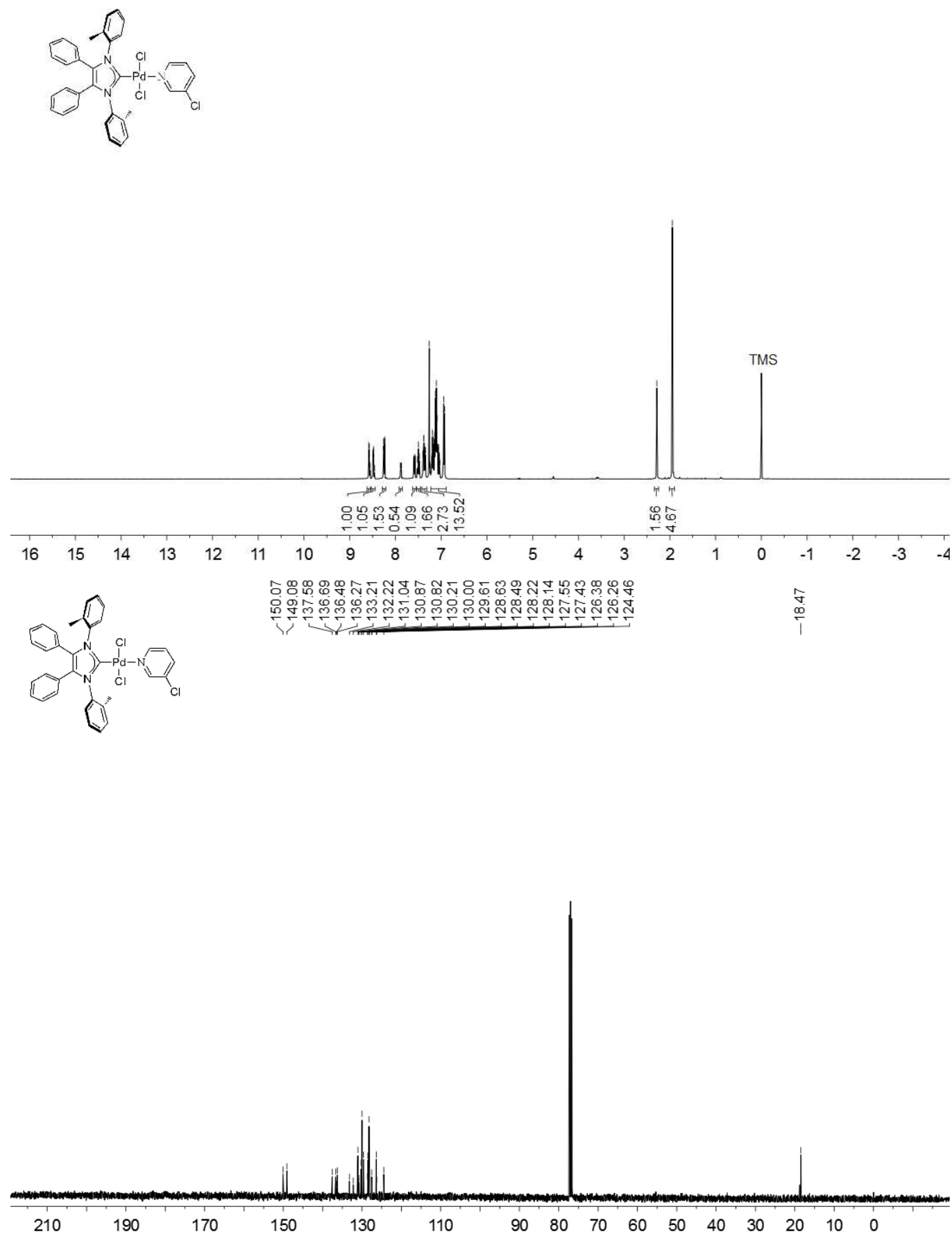
Figure S7. The NMR spectrums of the Pd-PEPPSI complex of $\mathbf{C 2}$.

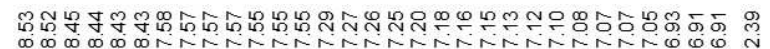

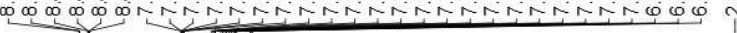
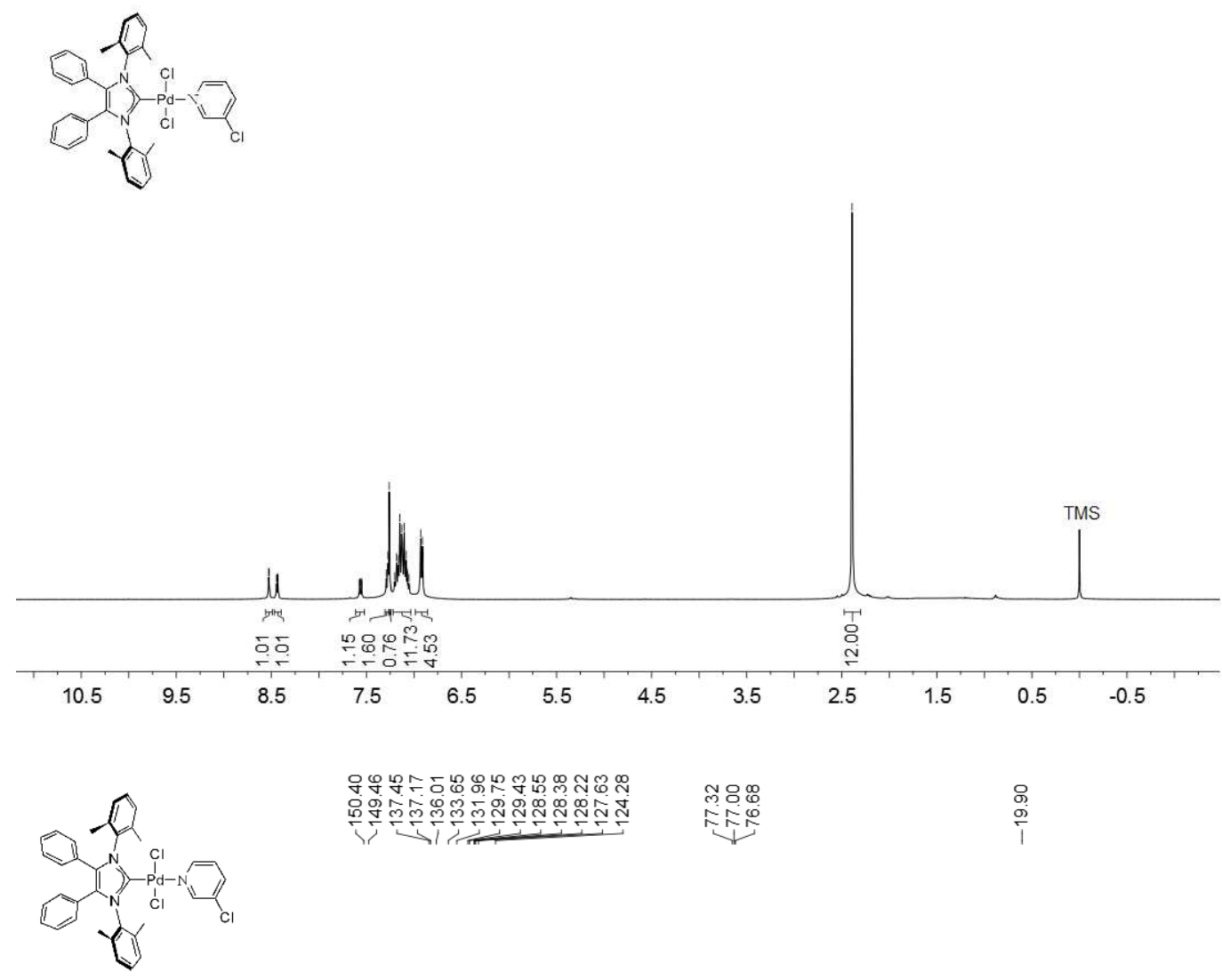

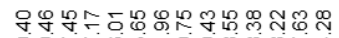

०.

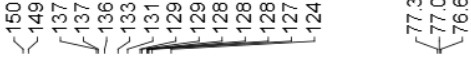

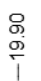

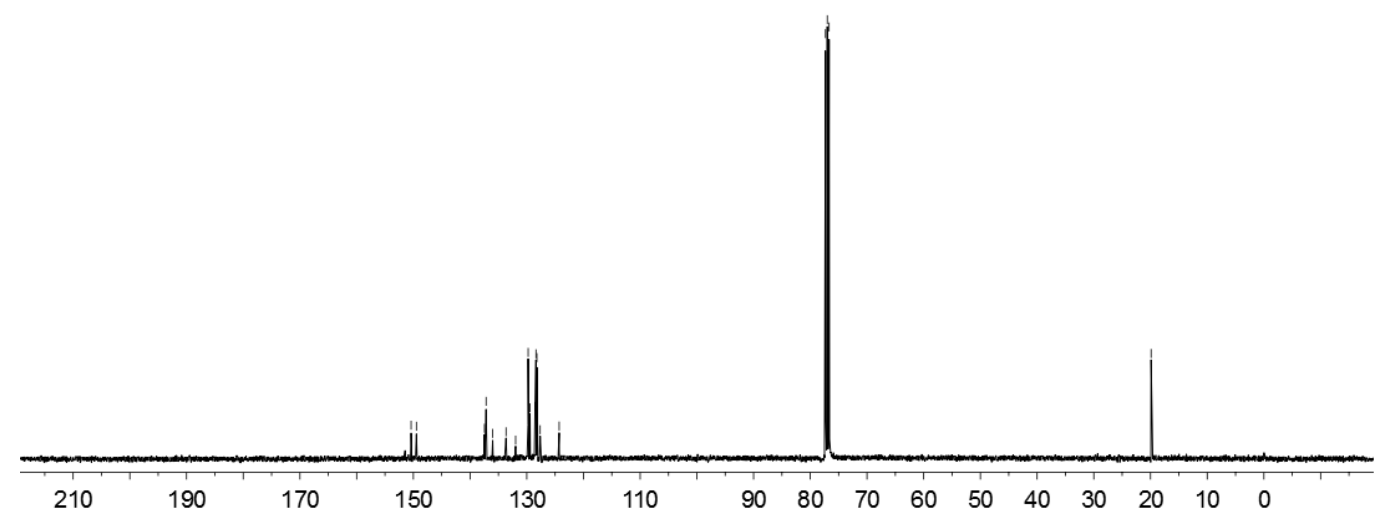


Figure S8. The NMR spectrums of the Pd-PEPPSI complex of C3.
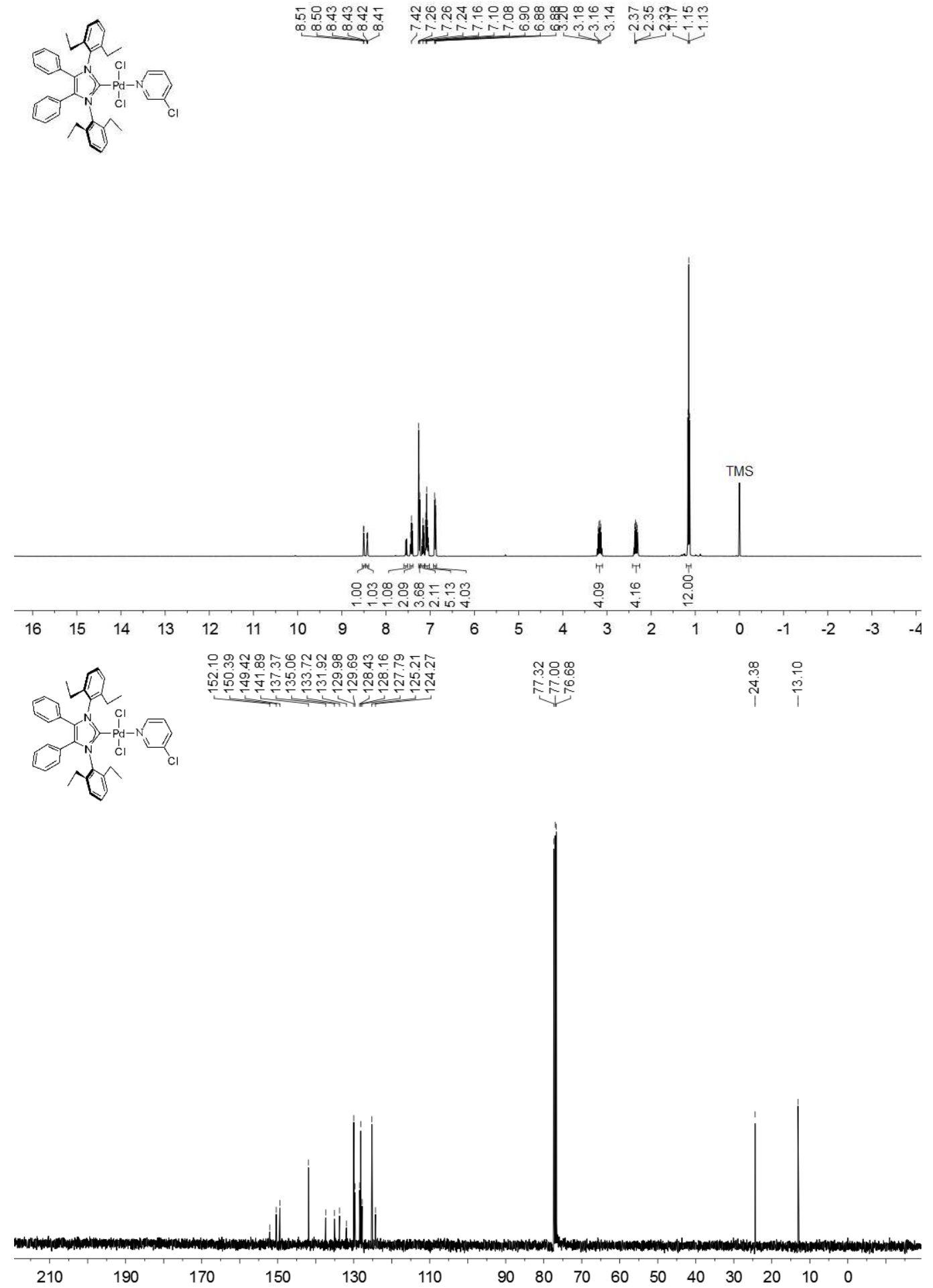
Figure S9. The NMR spectrums of the Pd-PEPPSI complex of $\mathbf{C 4}$.

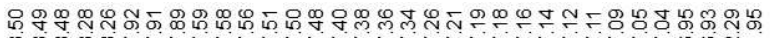

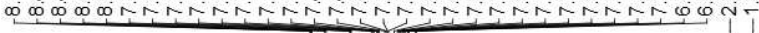
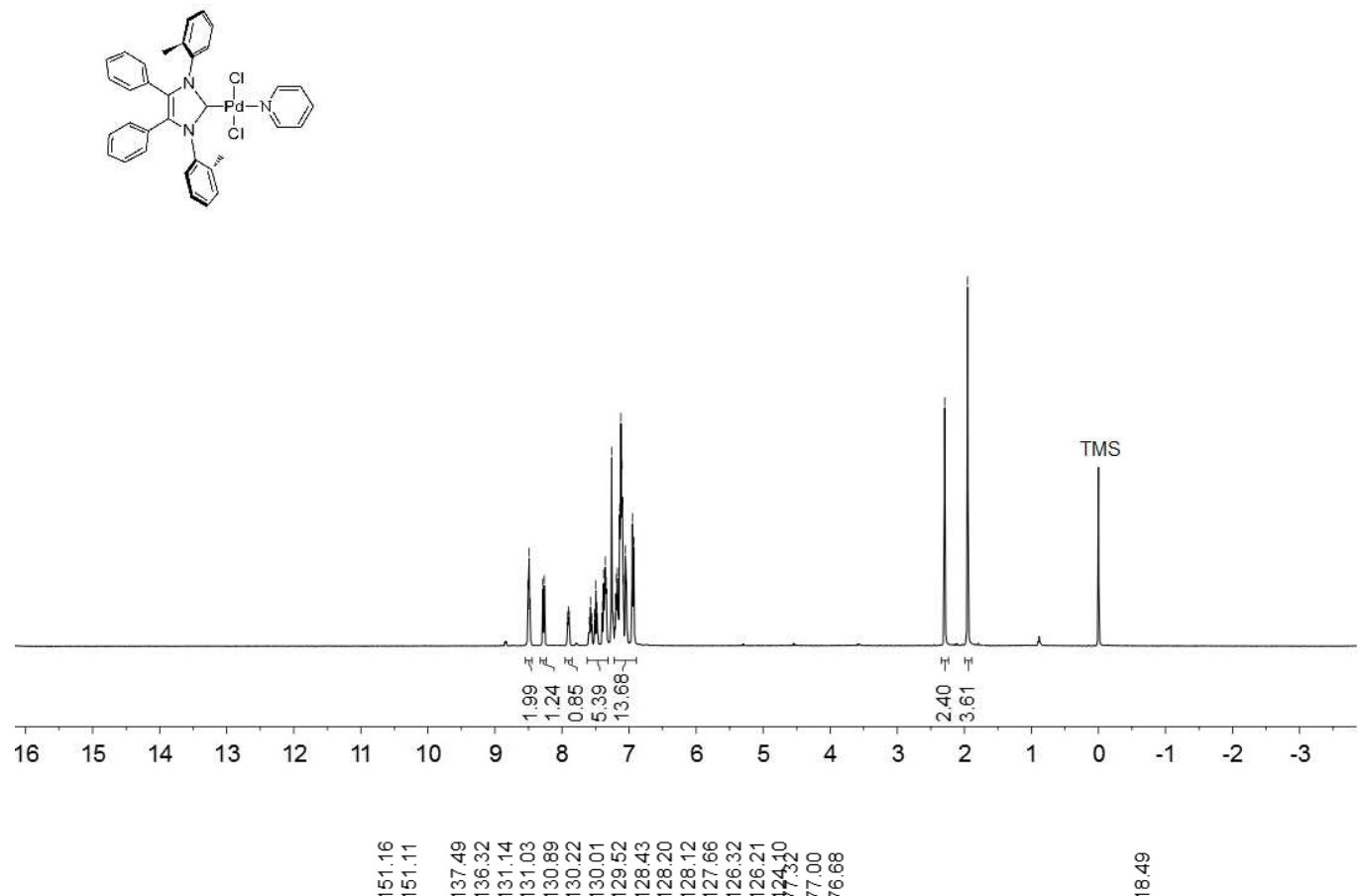

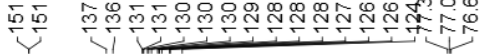
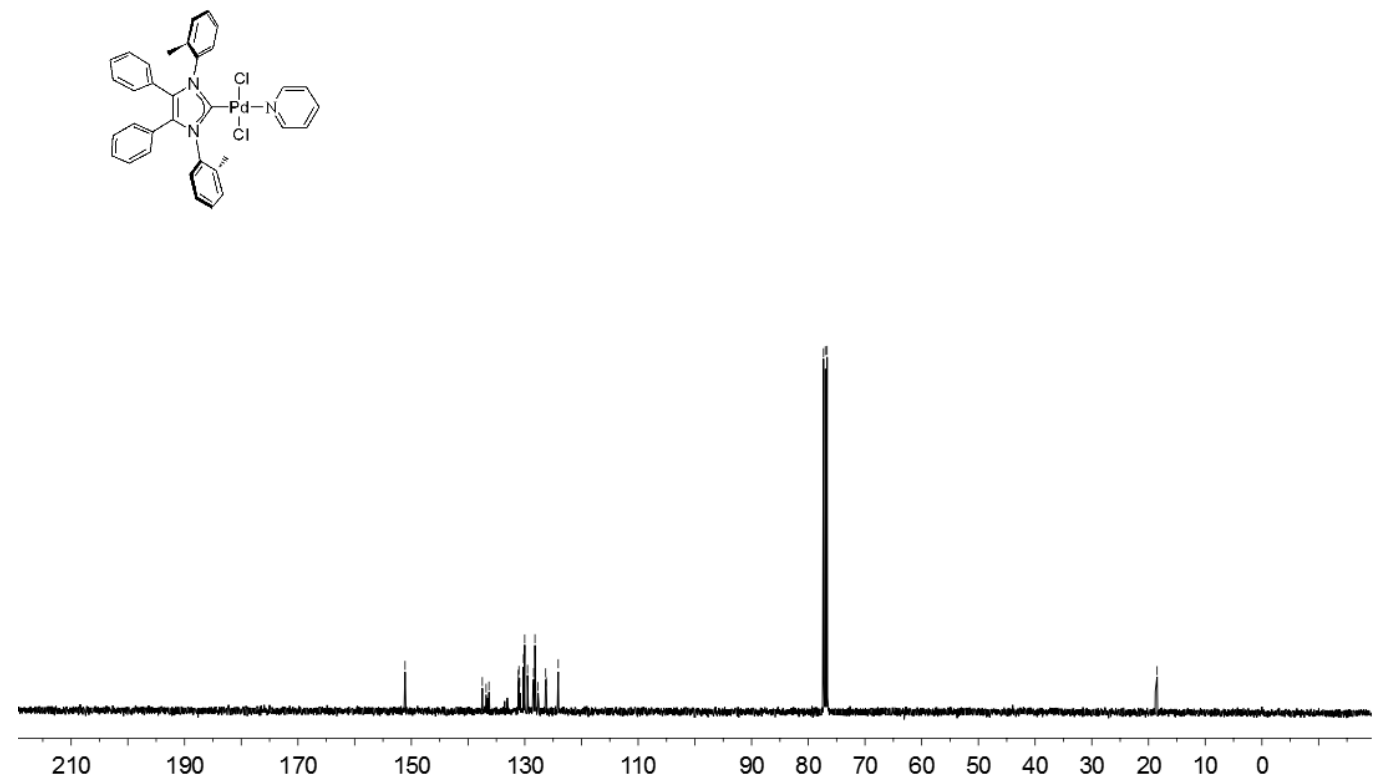
Figure S10. The NMR spectrums of the Pd-PEPPSI complex of C5.

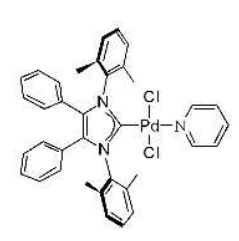

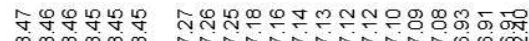
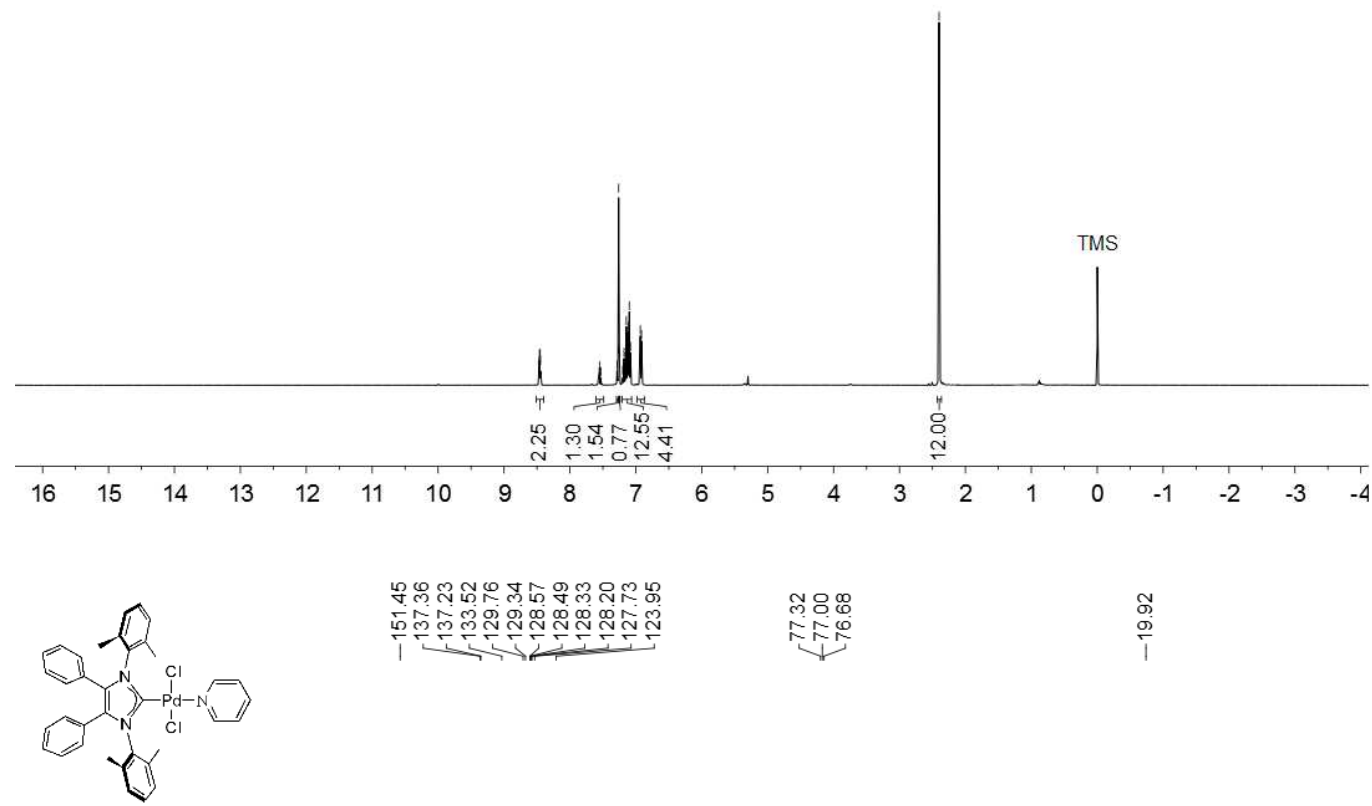

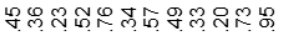

ำㄷำ

诲更

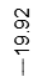

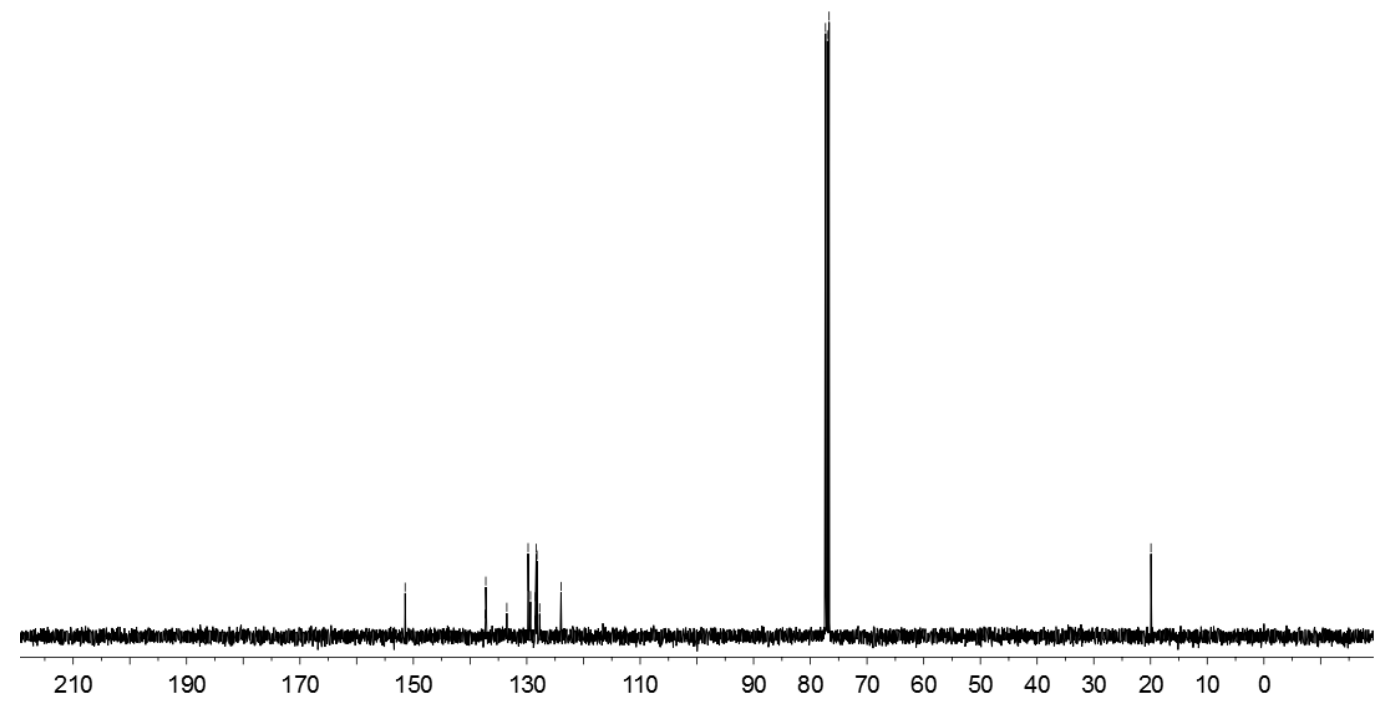


Figure S11. The NMR spectrums of the Pd-PEPPSI complex of C6.
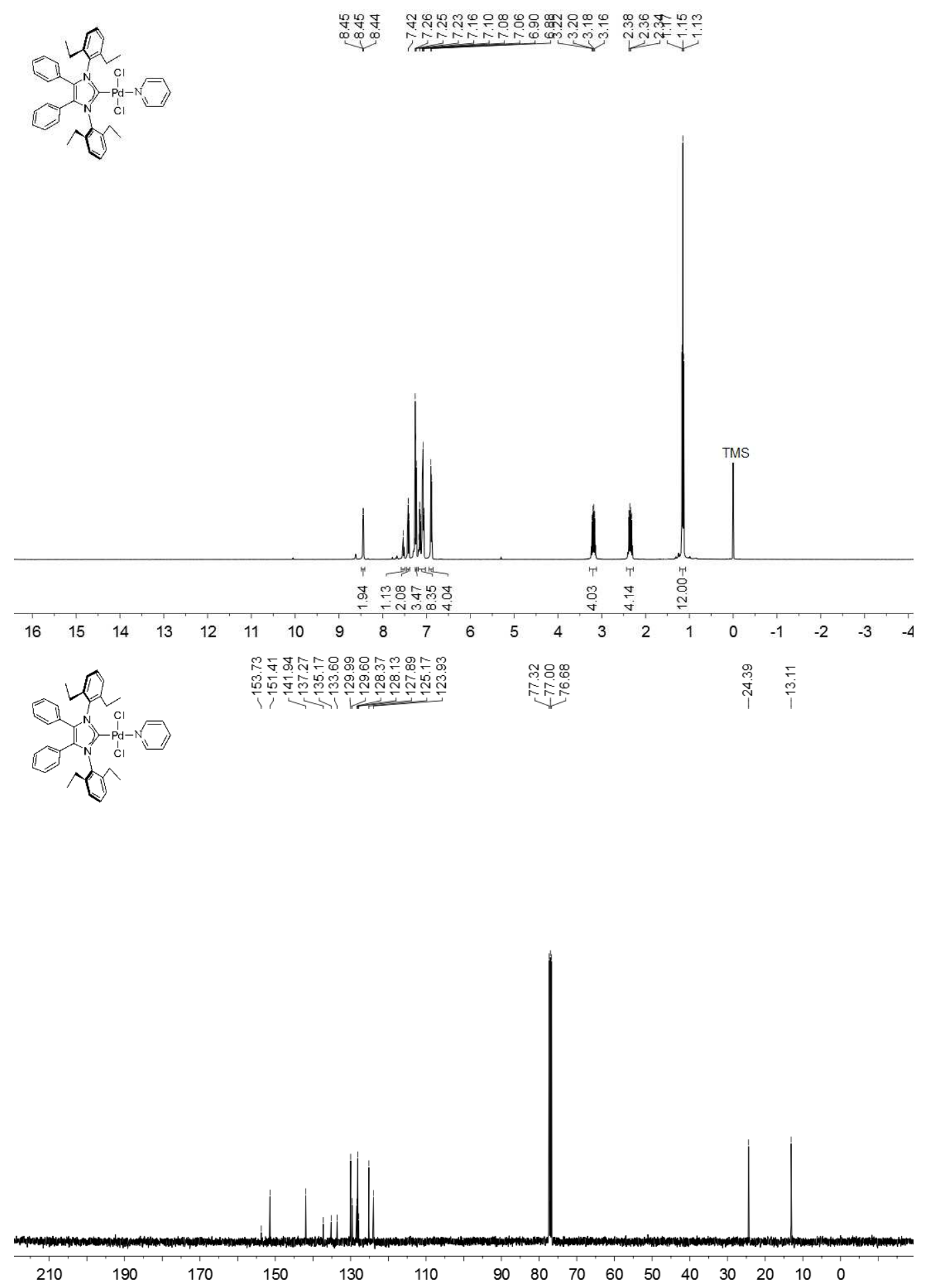
Figure S12. The NMR spectrums of 5-(4-chlorophenyl)-1-methyl-1H-imidazole (9aa)<smiles>Clc1ccc(C2CCCNC2)cc1</smiles>
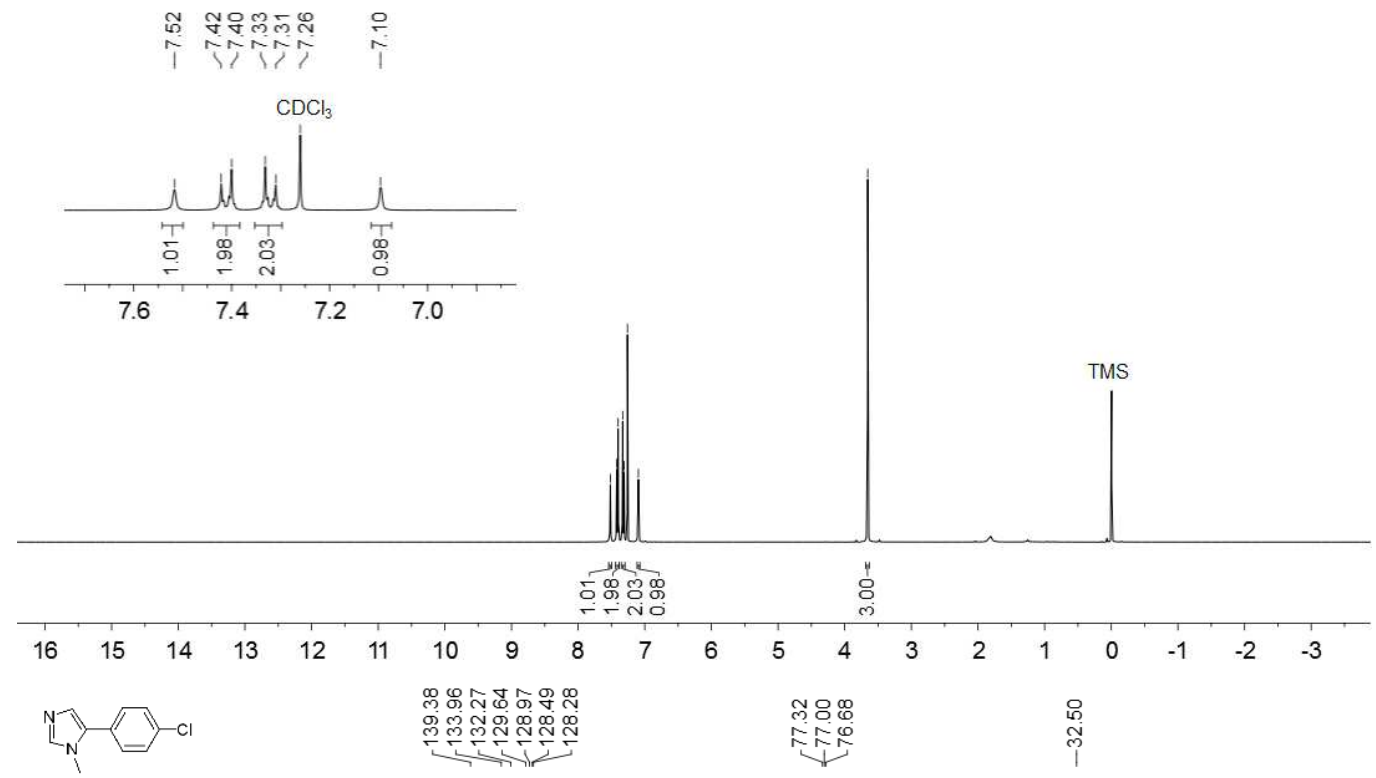

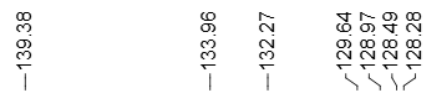
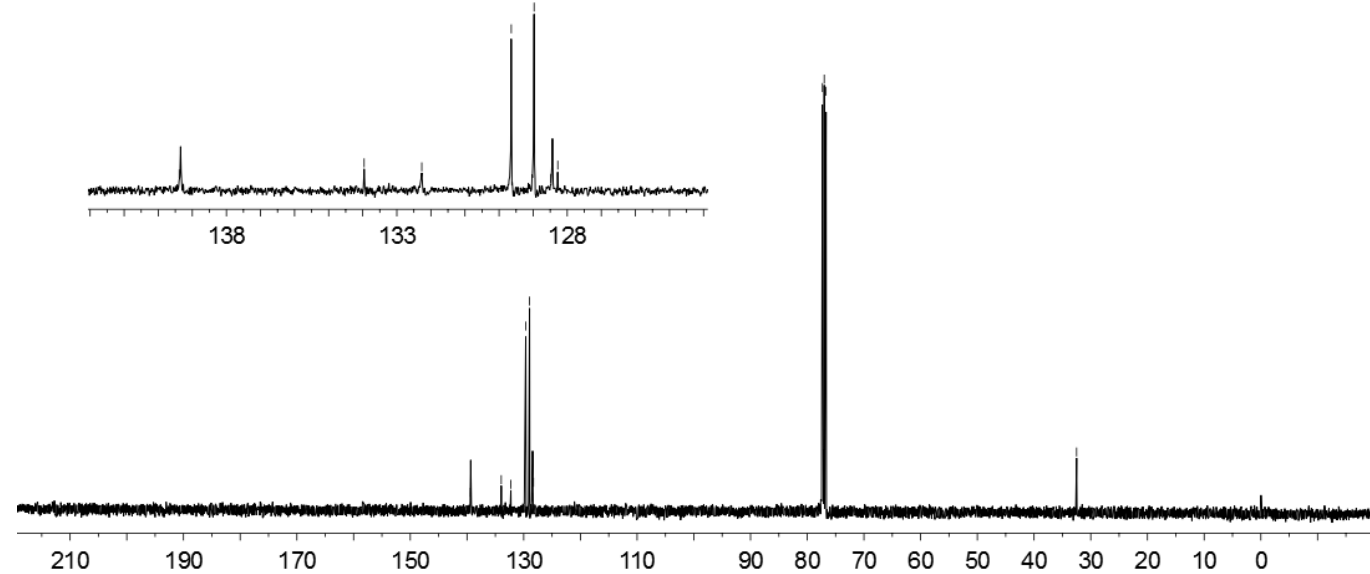
Figure S13. The NMR spectrums of methyl 4-(1-methyl-1H-imidazol-5-yl)benzoate (9ab)
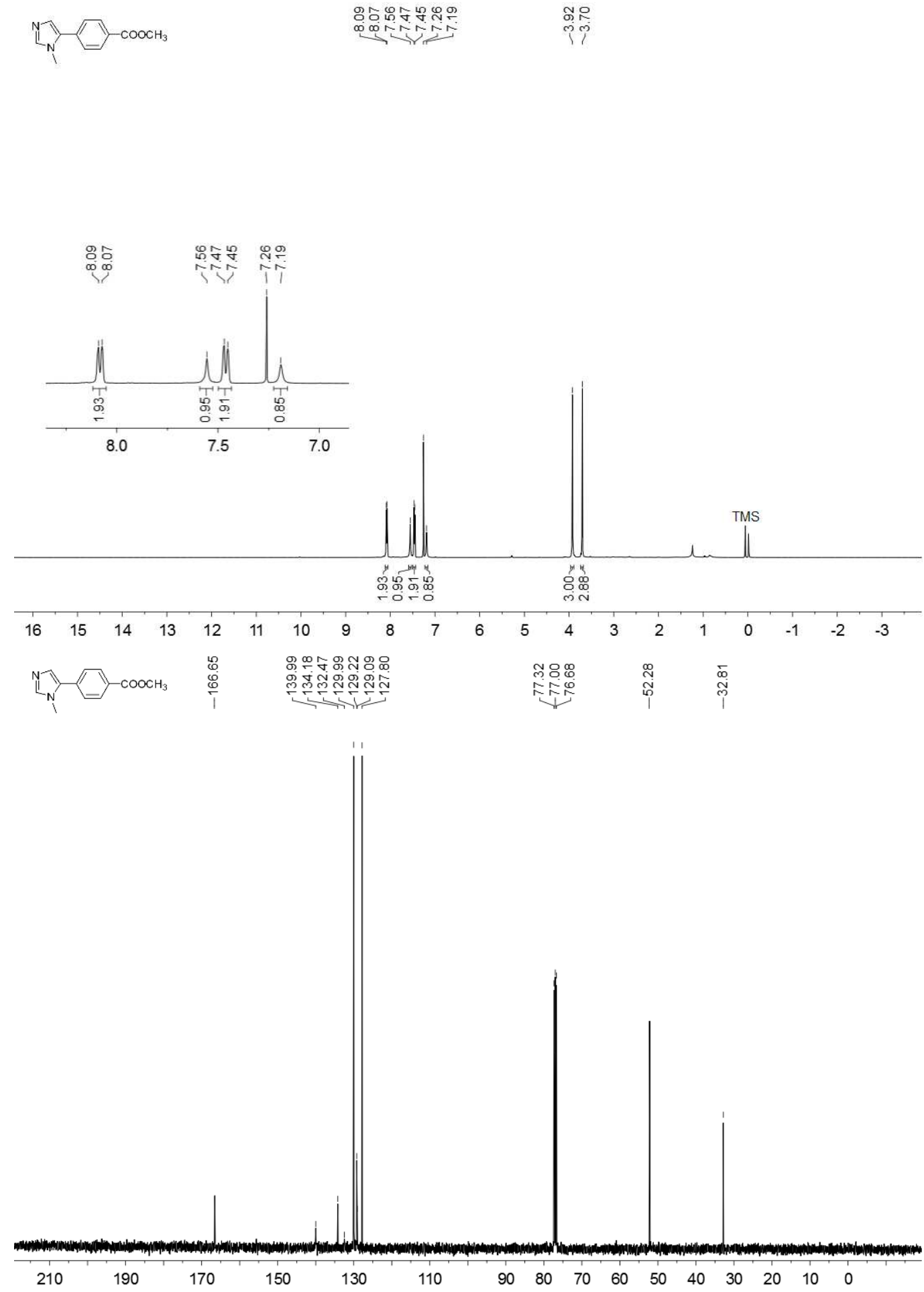
Figure S14. The NMR spectrums of 1-methyl-5-(4-nitrophenyl)-1H-imidazole (9ac)<smiles>CN1CNC=C1c1ccc([N+](=O)[O-])cc1</smiles>
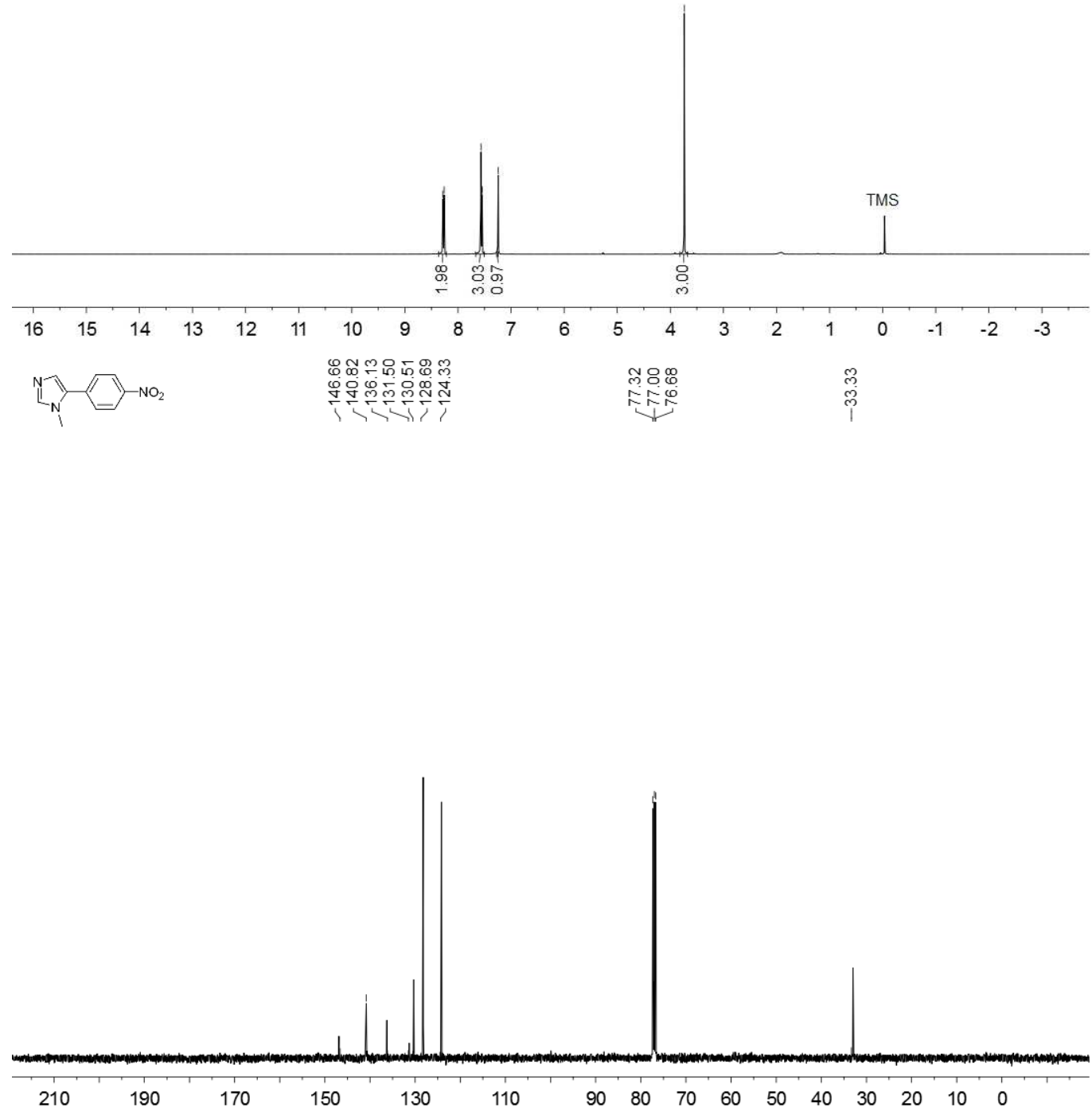
Figure S15. The NMR spectrums of 4-(1-methyl-1H-imidazol-5-yl)benzonitrile (9ad)<smiles>CN1CN=C1c1ccccc1</smiles>
동ำ
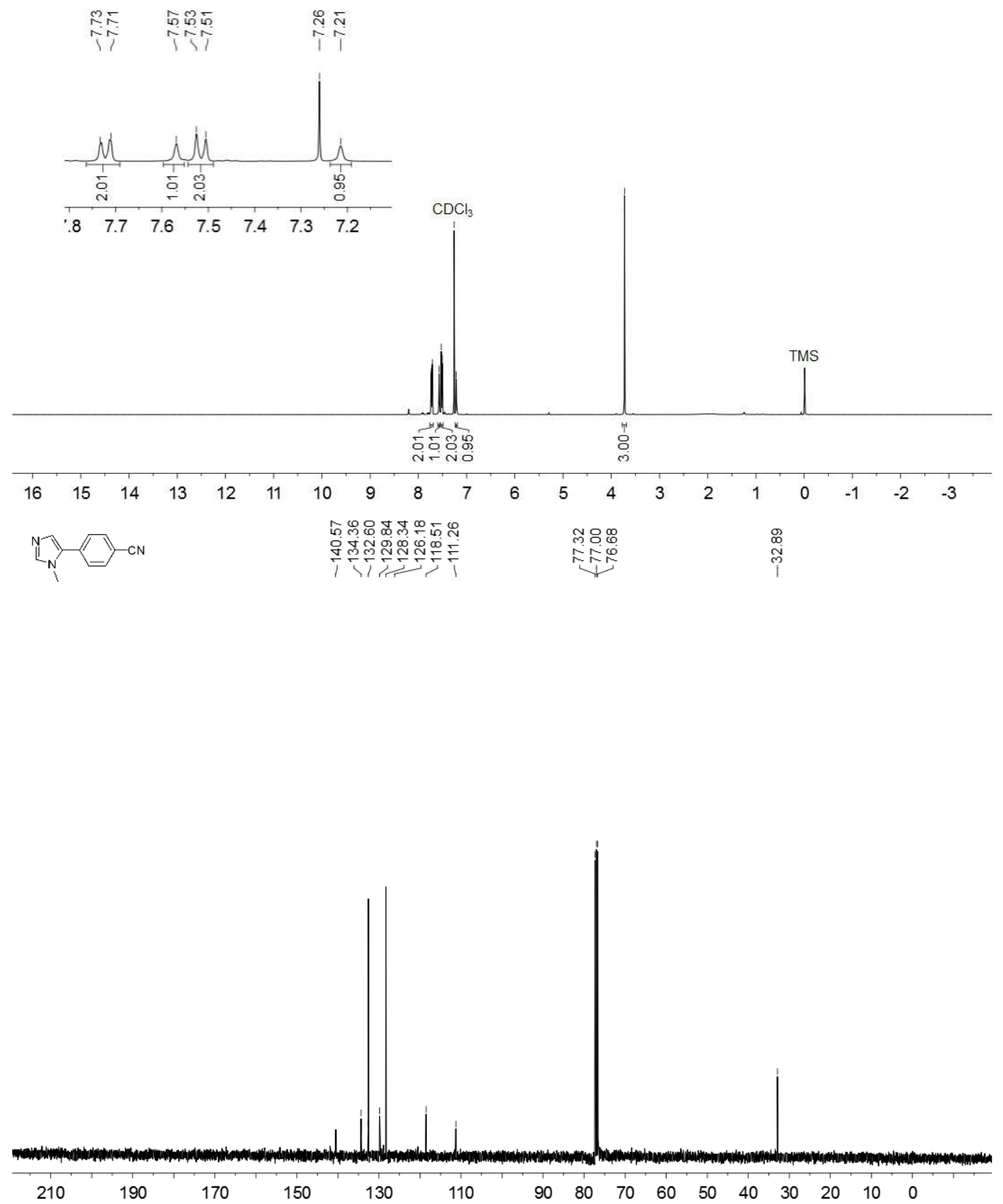
Figure S16. The NMR spectrums of 4-(1-methyl-1H-imidazol-5-yl)benzaldehyde (9ae)
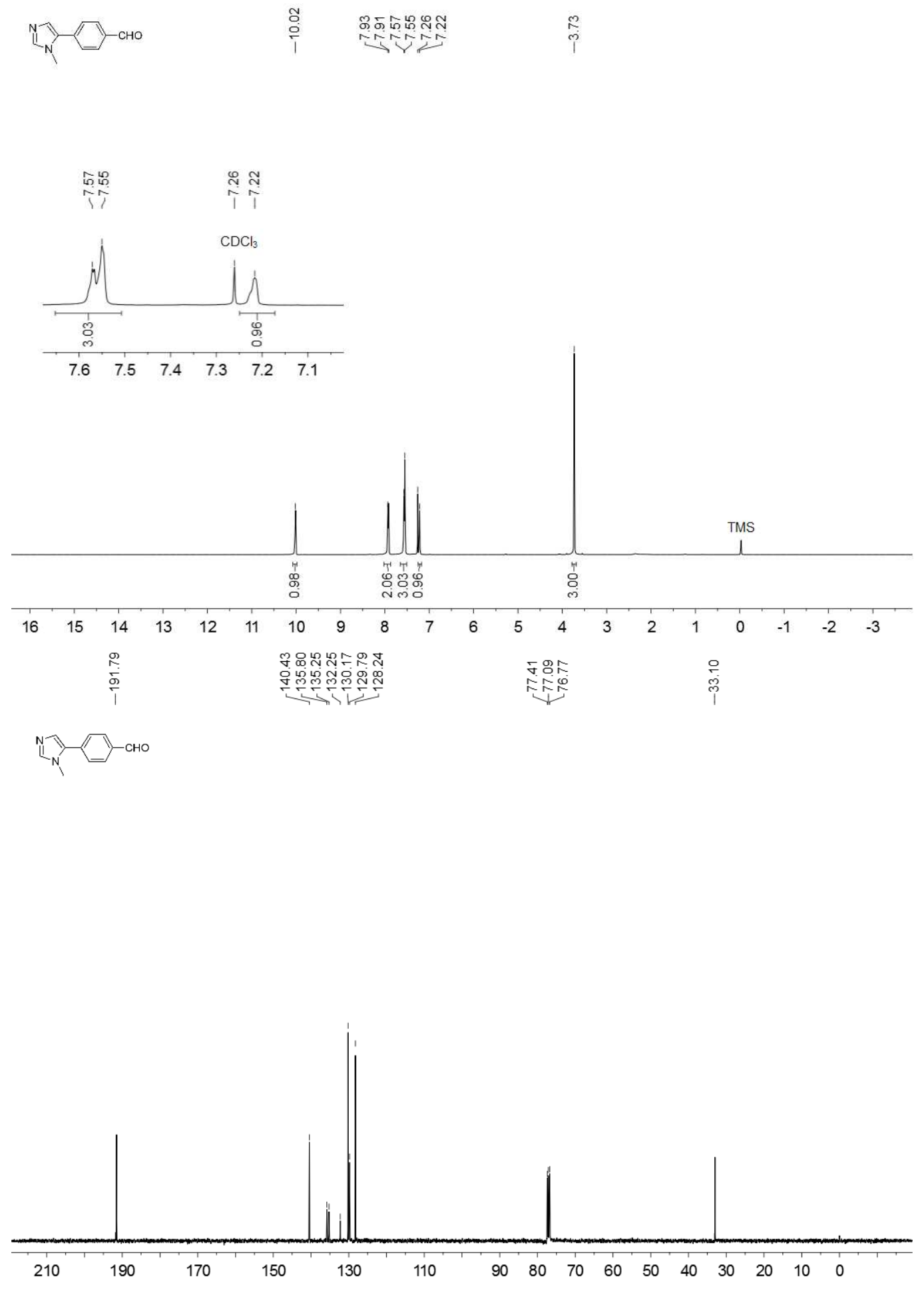
Figure S17. The NMR spectrums of 1-(4-(1-methyl-1H-imidazol-5-yl)phenyl)ethanone (9af)
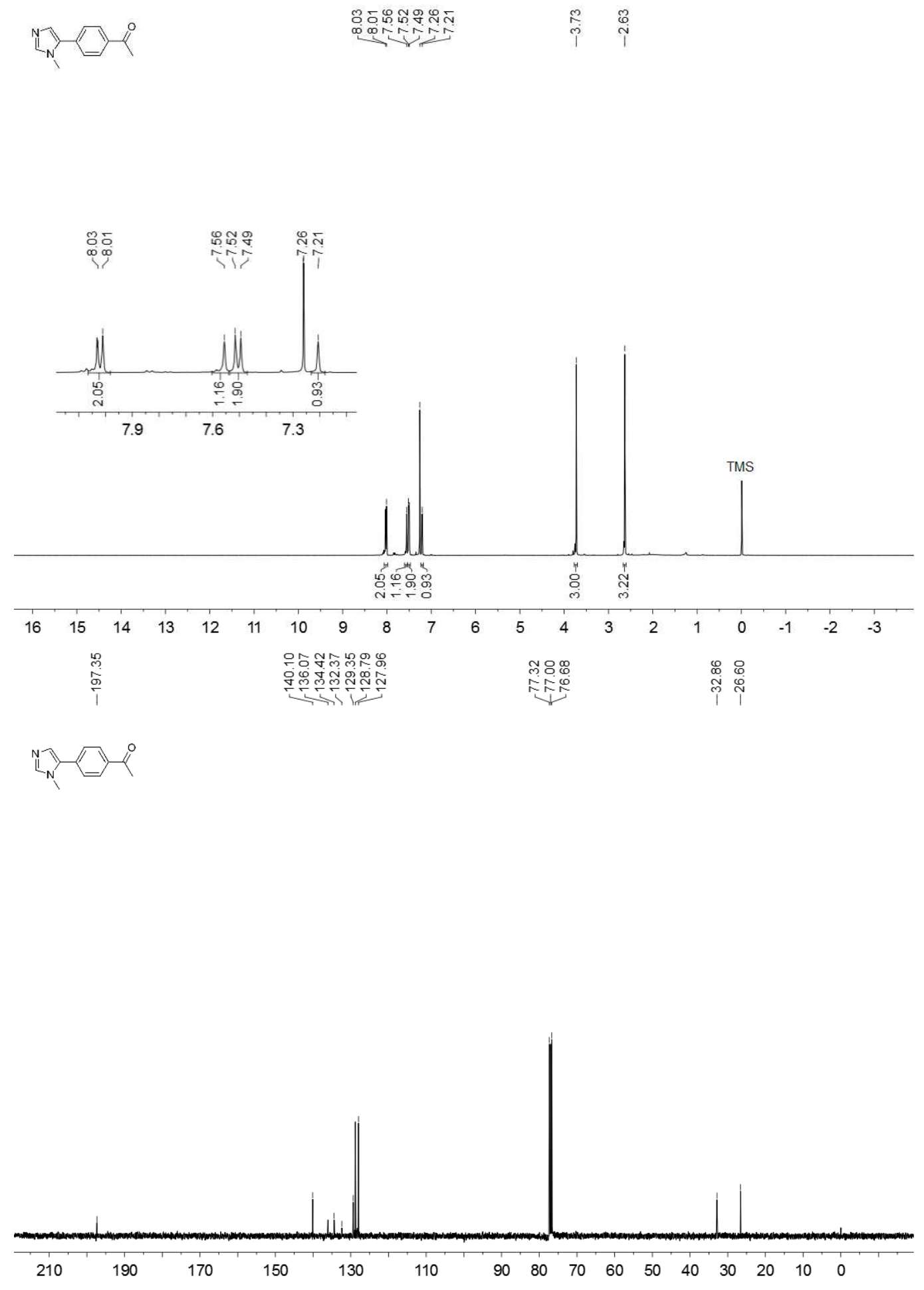
$\begin{array}{lllll}\text { Figure } & \text { S18. } & \text { The } & \text { NMR }\end{array}$ 1-methyl-5-(4-(trifluoromethyl)phenyl)-1H-imidazole (9ag)
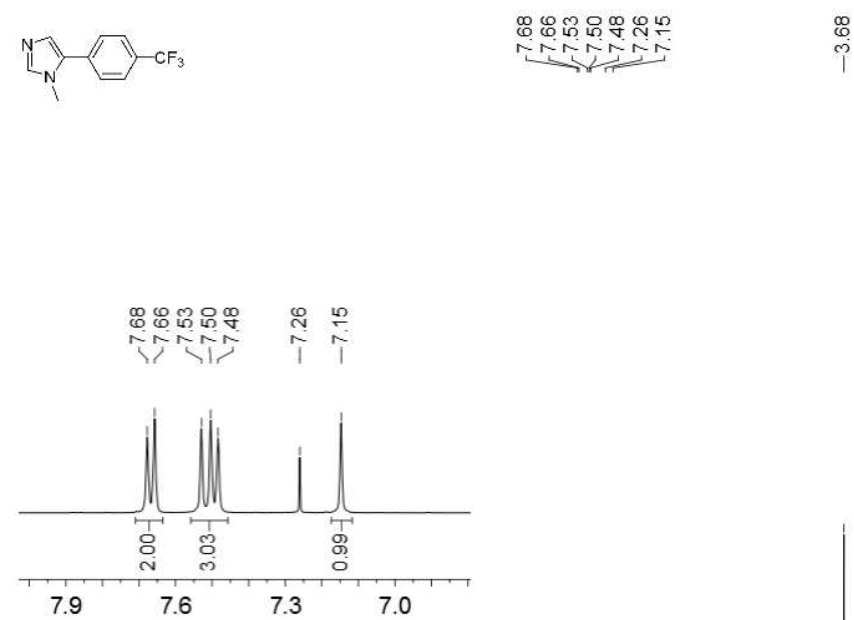

\section{i}
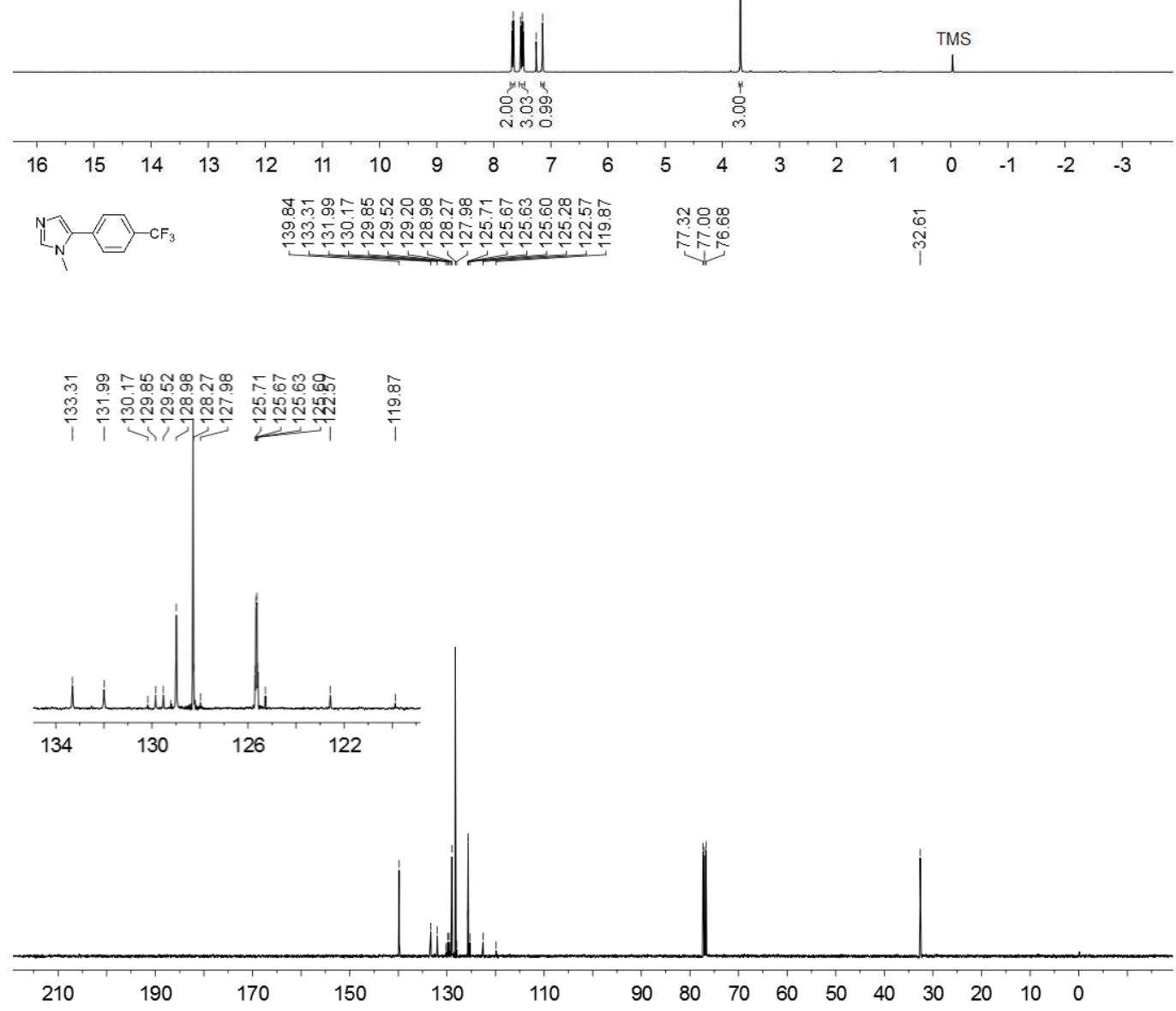
Figure S19. The NMR spectrums of 5-(4-fluorophenyl)-1-methyl-1H-imidazole (9ah)<smiles>C1CCC(C2C3CCCC2CCC3)CC1</smiles>
年
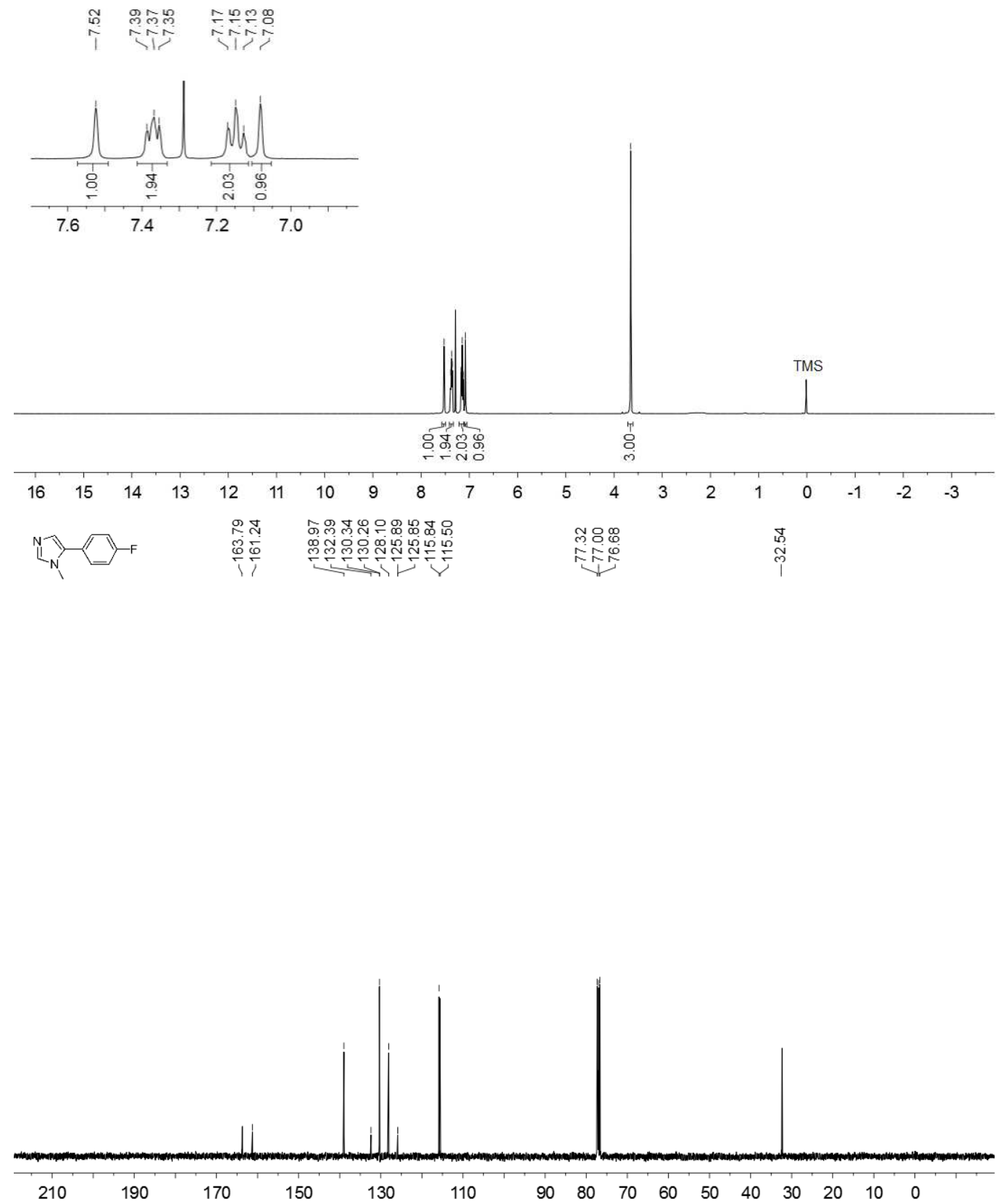
Figure S20. The NMR spectrums of 1-methyl-5-phenyl-1H-imidazole (9ai)
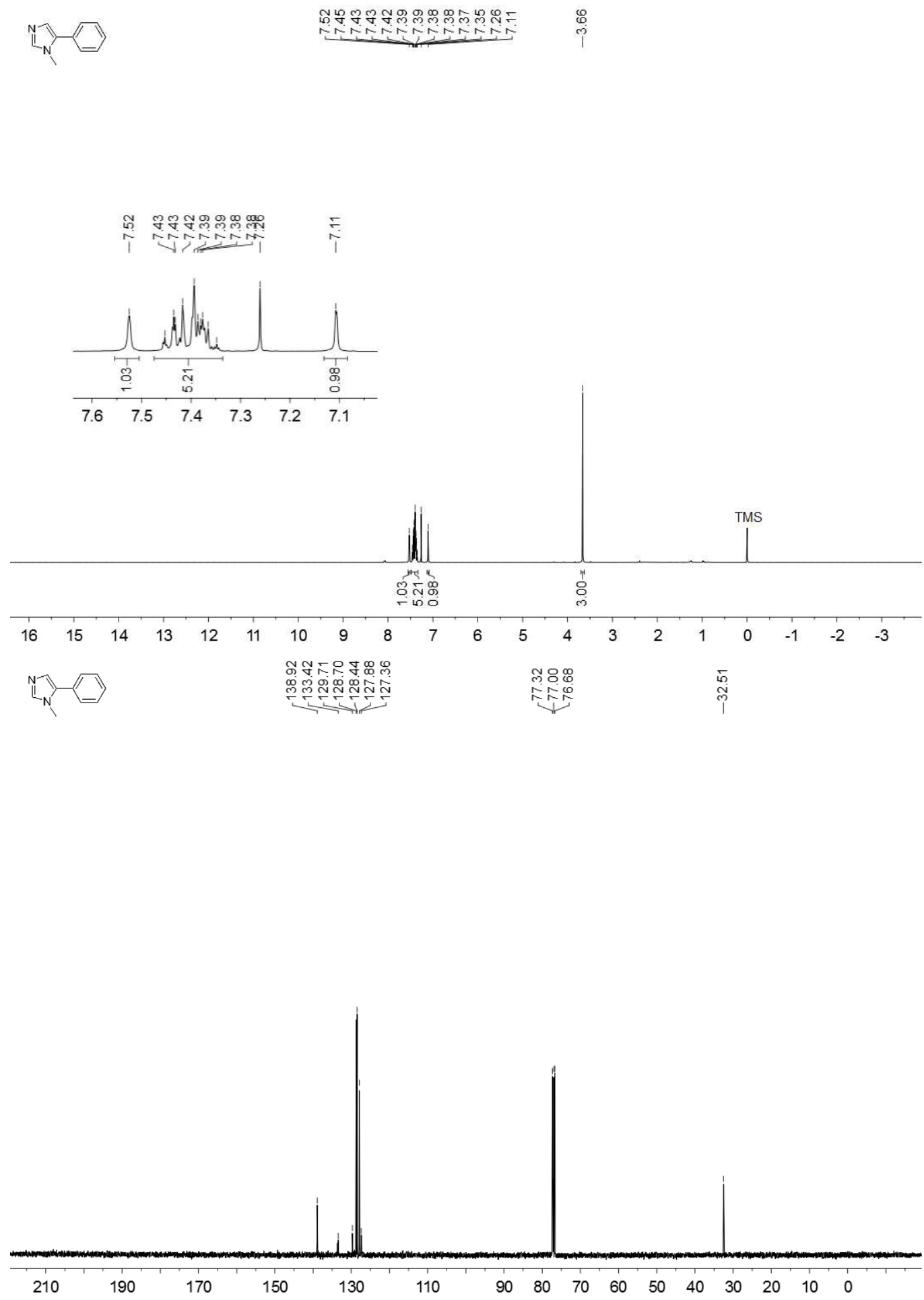
Figure S21. The NMR spectrums of 1-methyl-5-(naphthalen-1-yl)-1H-imidazole (9aj)
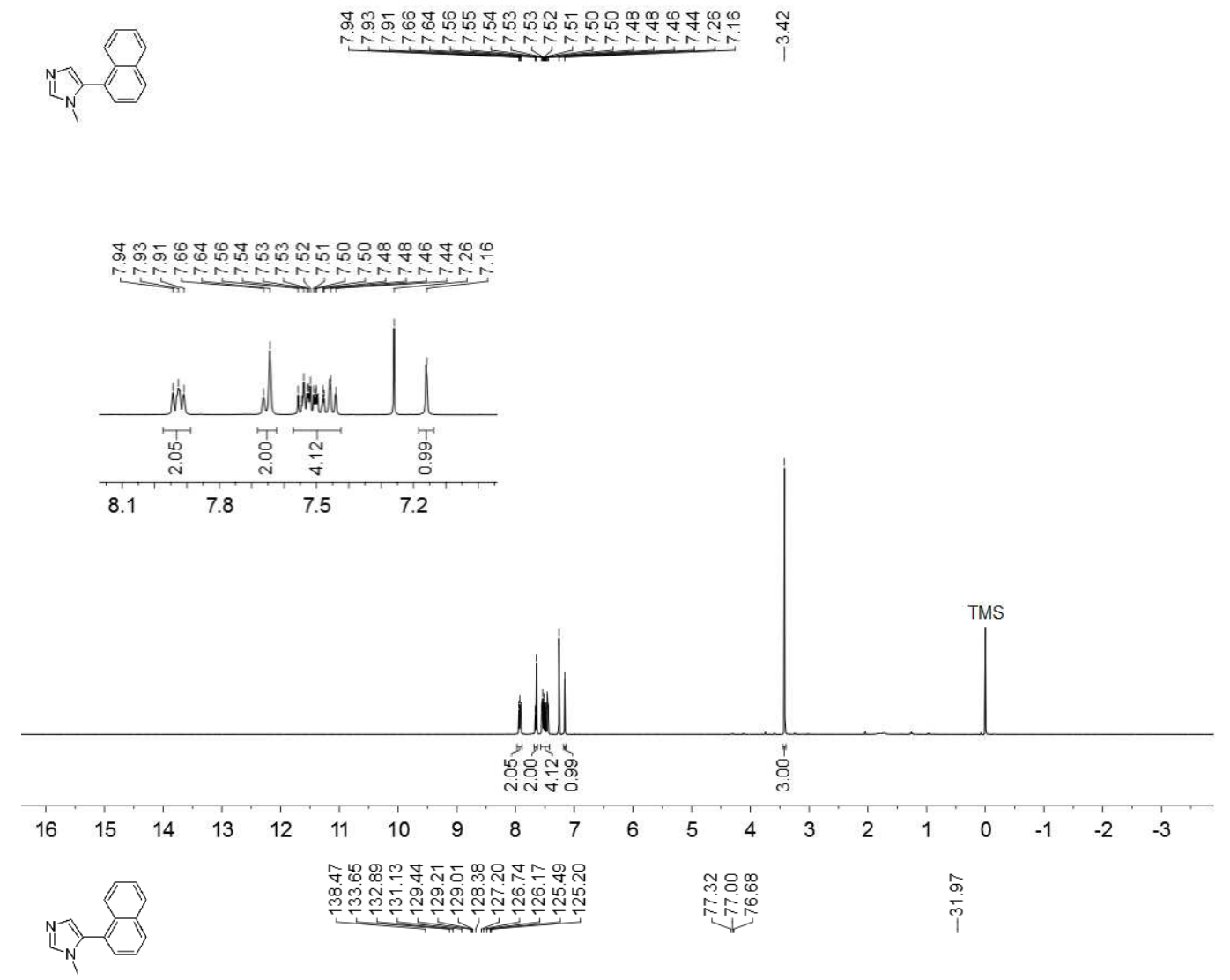

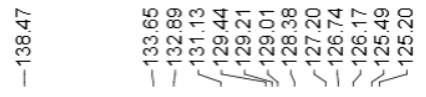
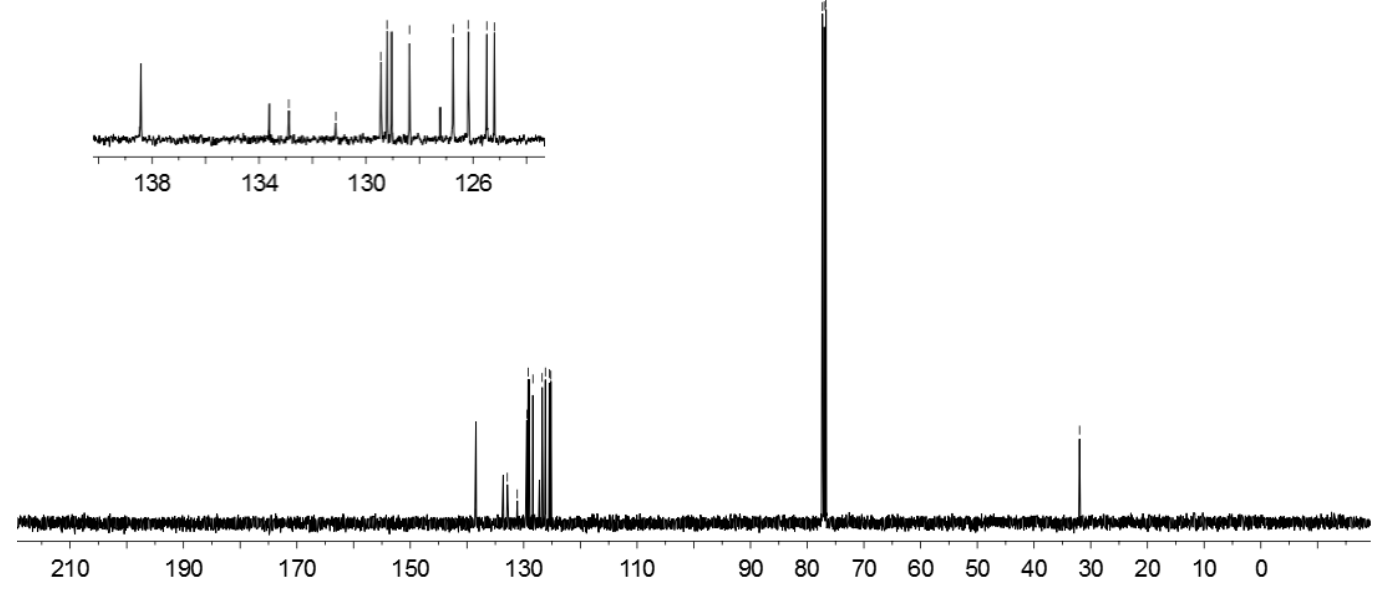
Figure S22. The NMR spectrums of 5-(3-methoxyphenyl)-1-methyl-1H-imidazole (9ak)
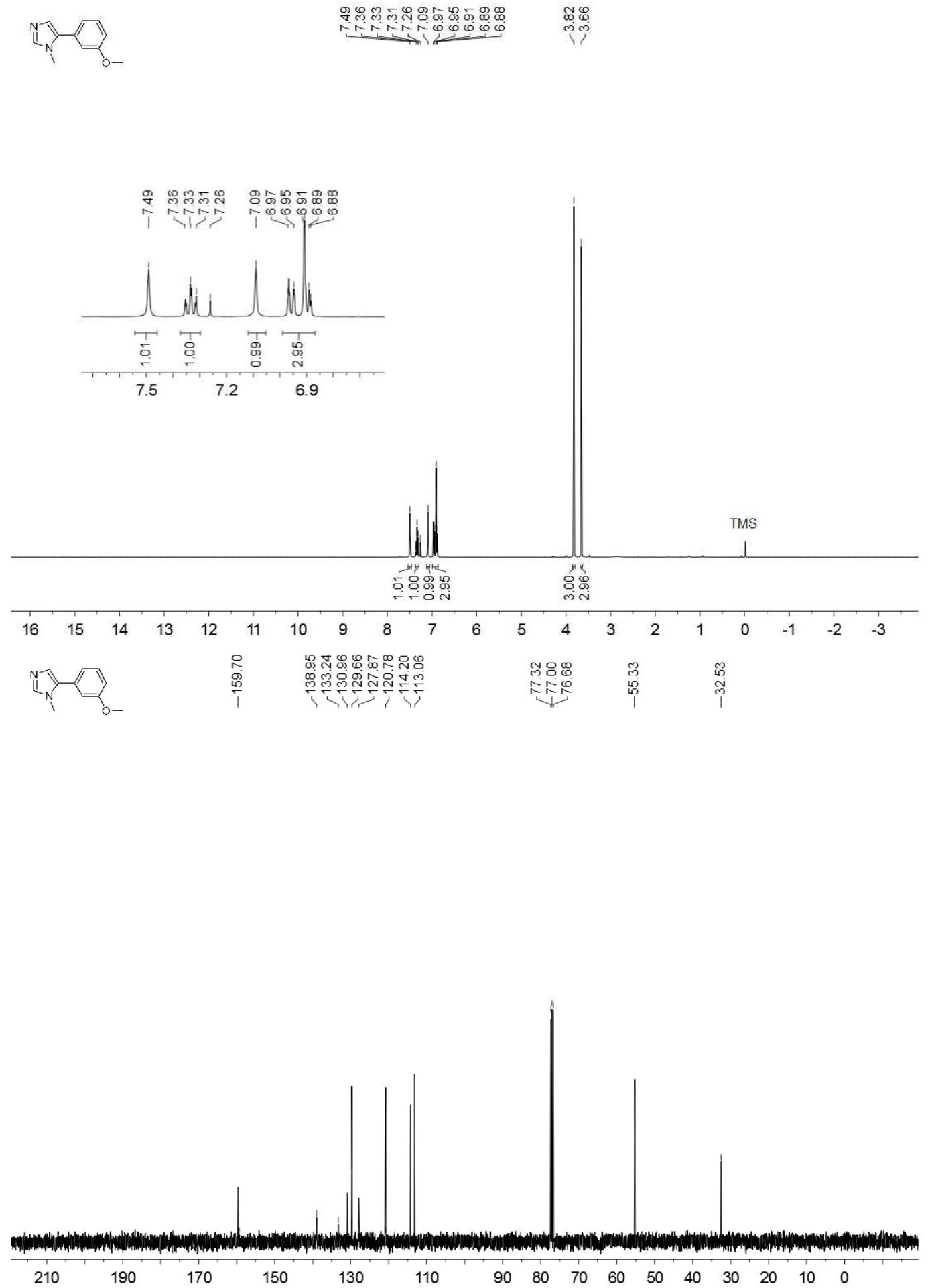
Figure S23. The NMR spectrums of 4-(1-methyl-1H-imidazol-5-yl)isoquinoline (9al)

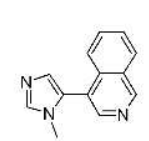

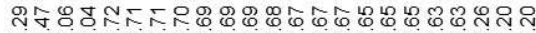
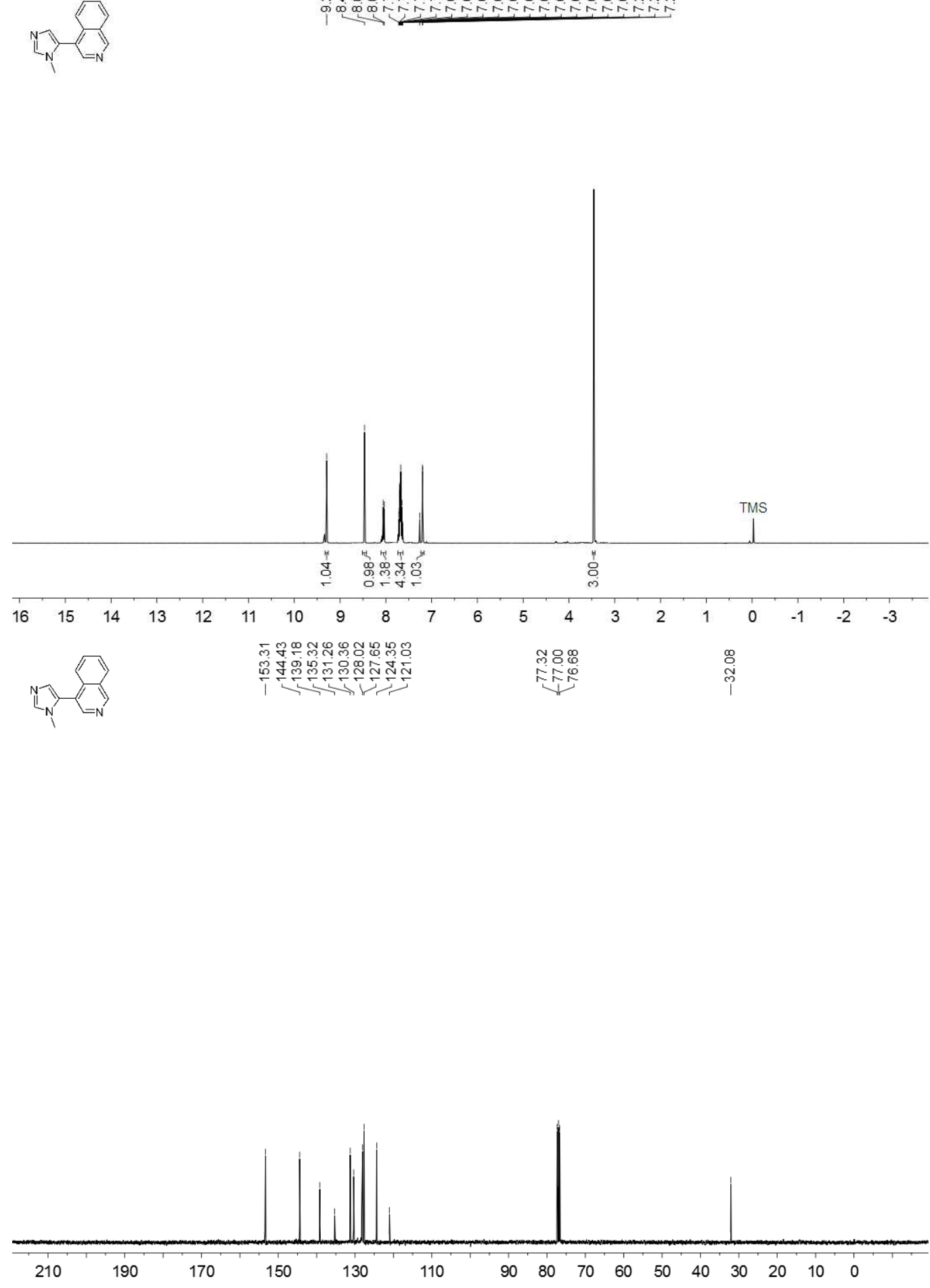
Figure S24. The NMR spectrums of 5-(4-chlorophenyl)-1,2-dimethyl-1H-imidazole (9ba)
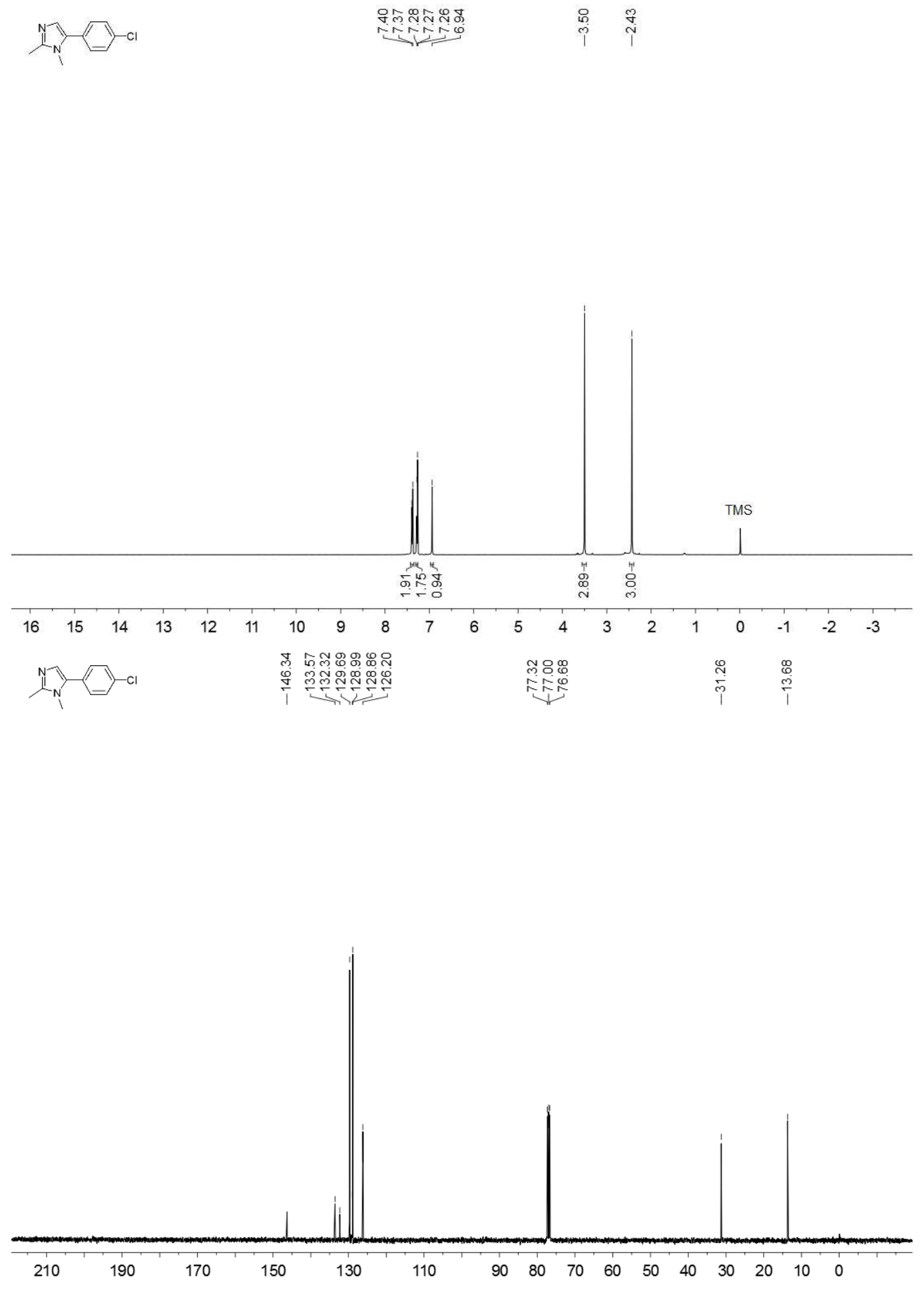
Figure S25. The NMR spectrums of methyl 4-(1,2-dimethyl-1H-imidazol-5-yl)benzoate (9bb)
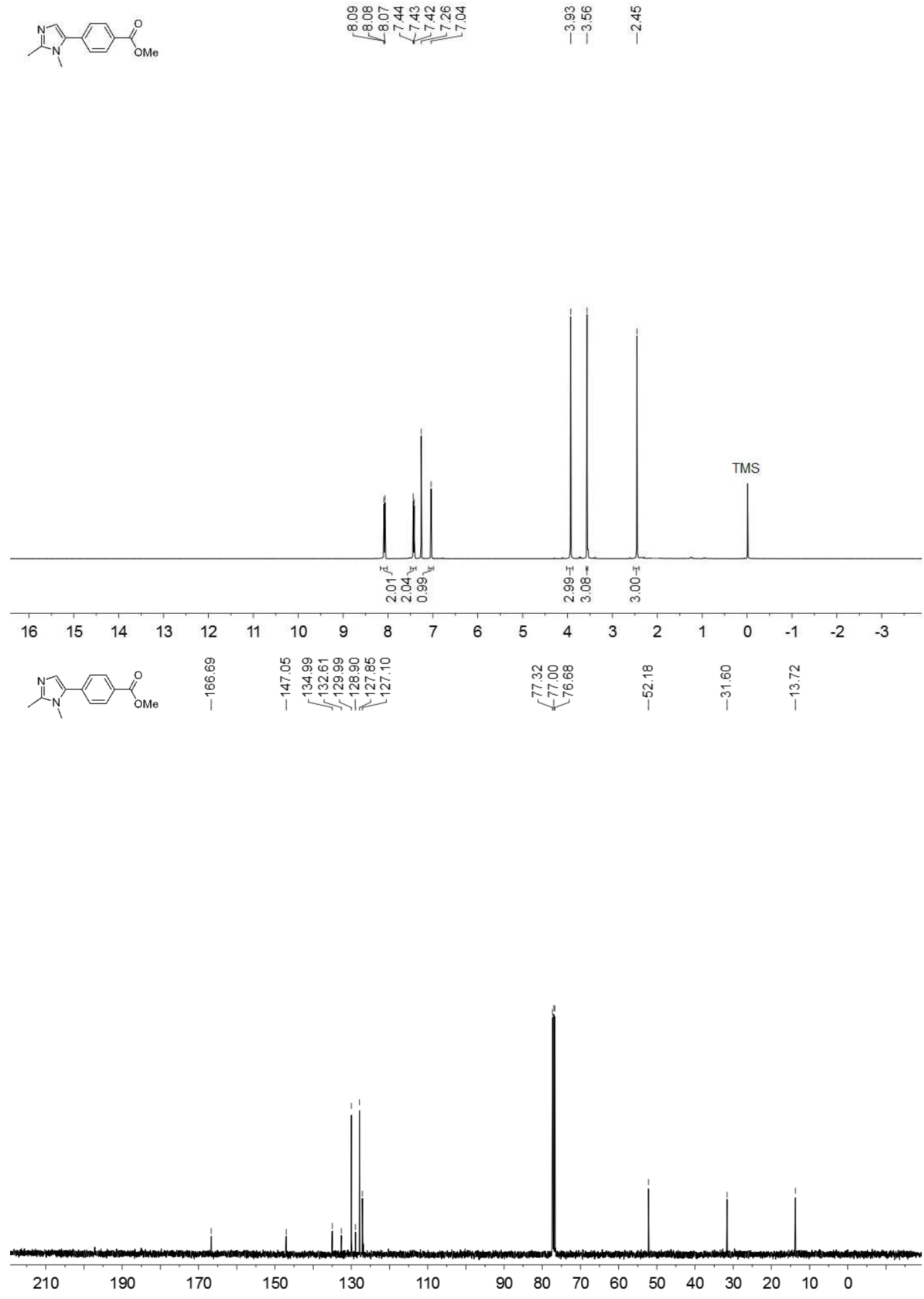
Figure S26. The NMR spectrums of methyl 1,2-dimethyl-5-(4-nitrophenyl)-1H-imidazole (9bc)
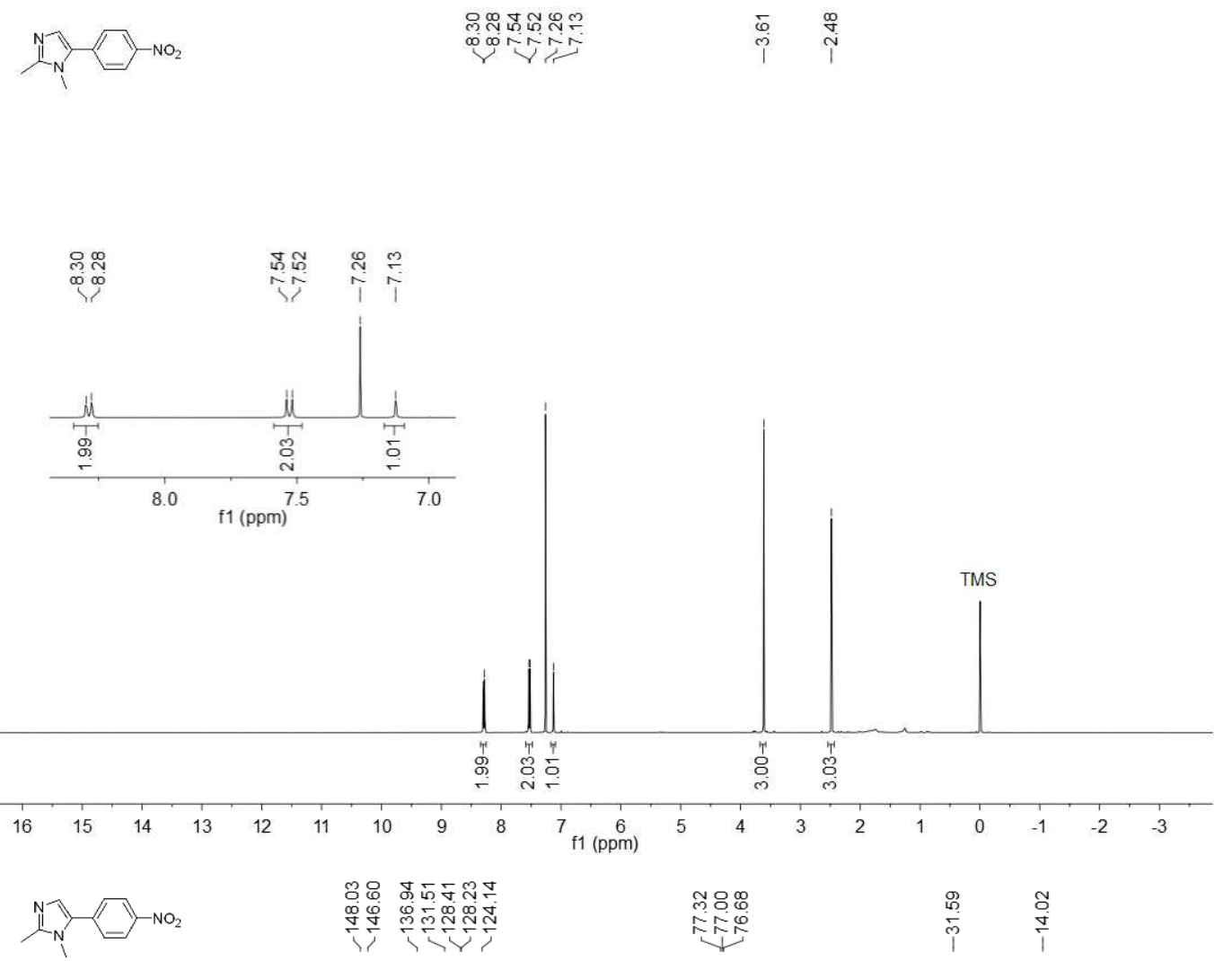

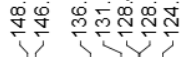

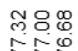

篎

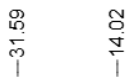

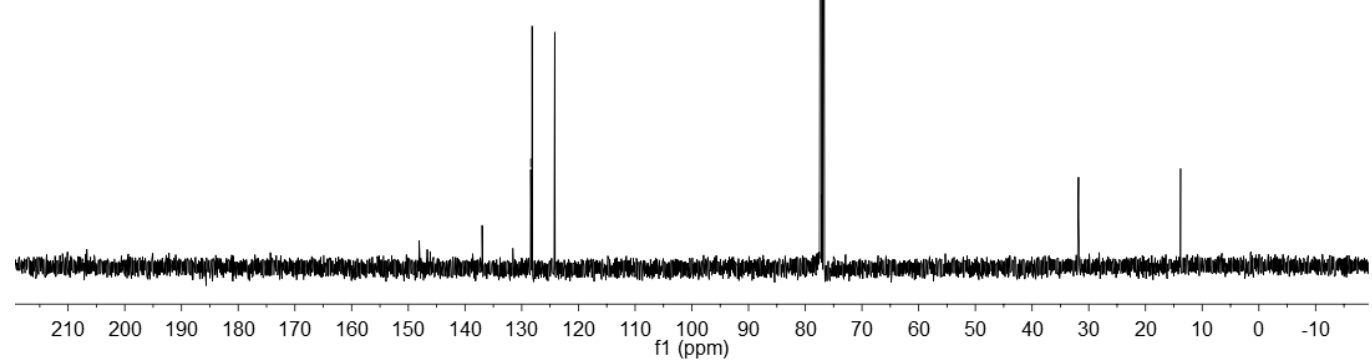


Figure S27. The NMR spectrums of methyl 4-(1,2-dimethyl-1H-imidazol-5-yl)benzonitrile (9bd)<smiles>Cc1ncc(-c2ccc(C#N)cc2)n1C</smiles>
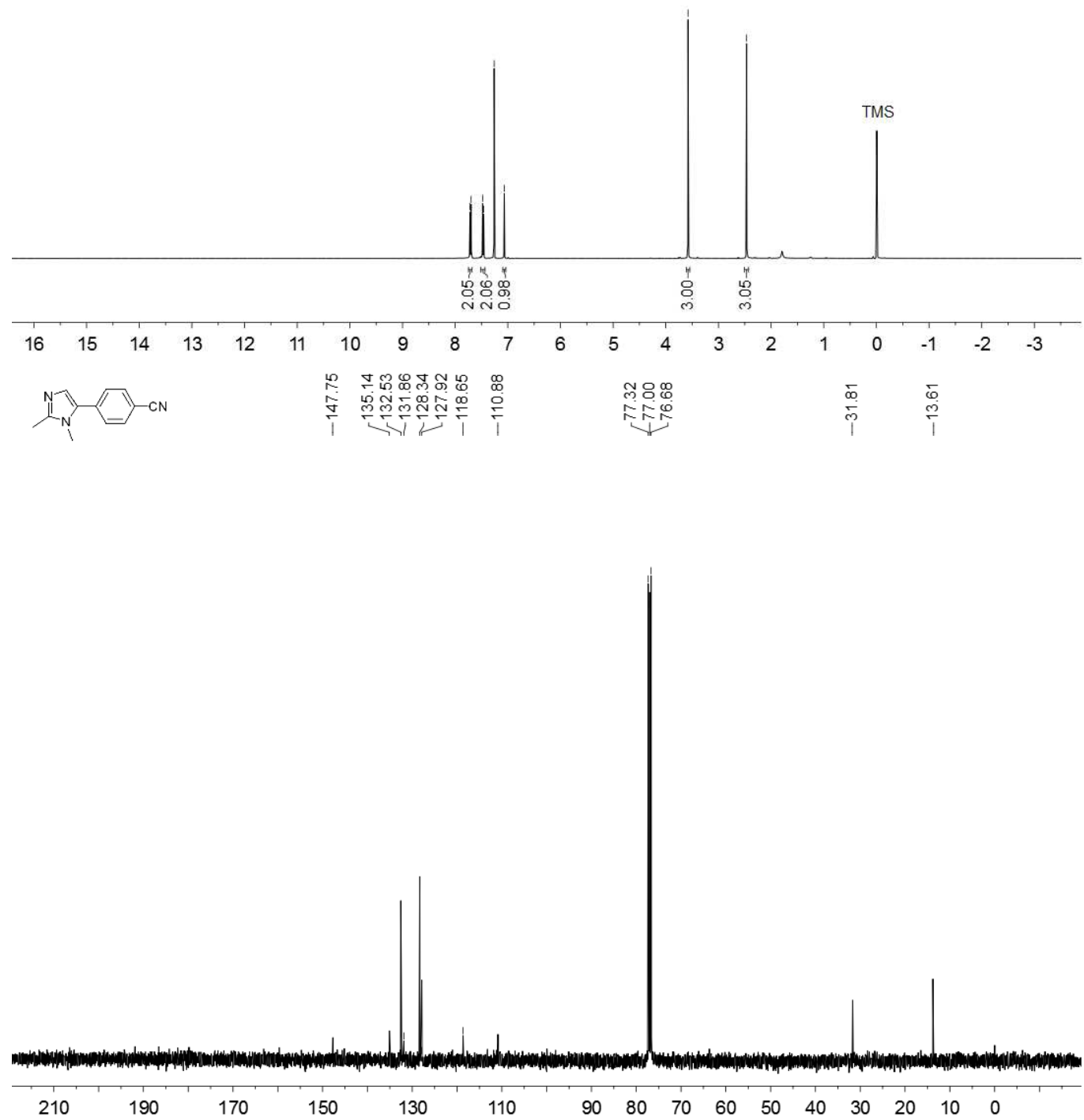
Figure S28. The NMR spectrums of 4-(1,2-dimethyl-1H-imidazol-5-yl)benzaldehyde (9be)
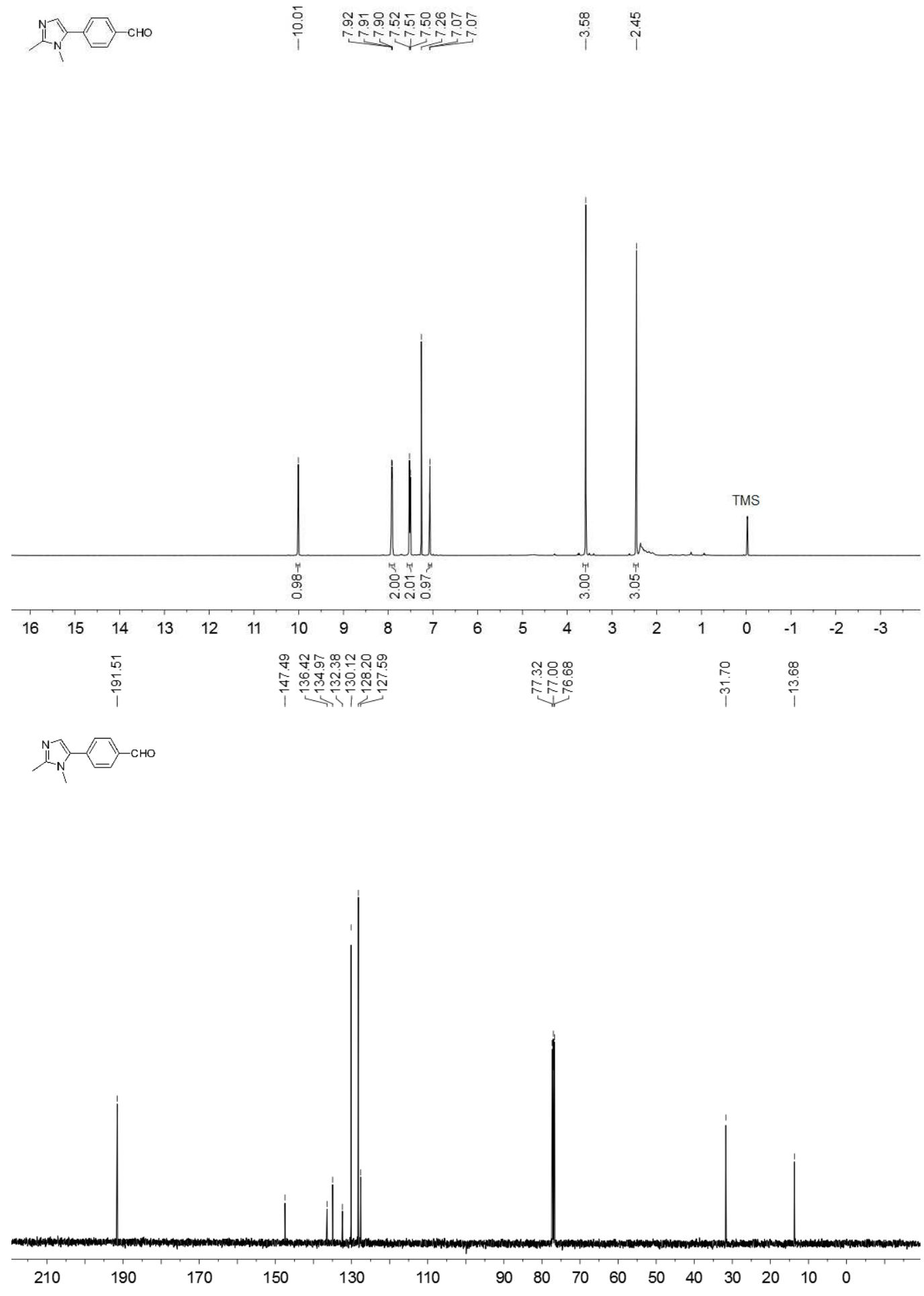
Figure S29. The NMR spectrums of 1-(4-(1,2-dimethyl-1H-imidazol-5-yl)phenyl)ethanone (9bf)
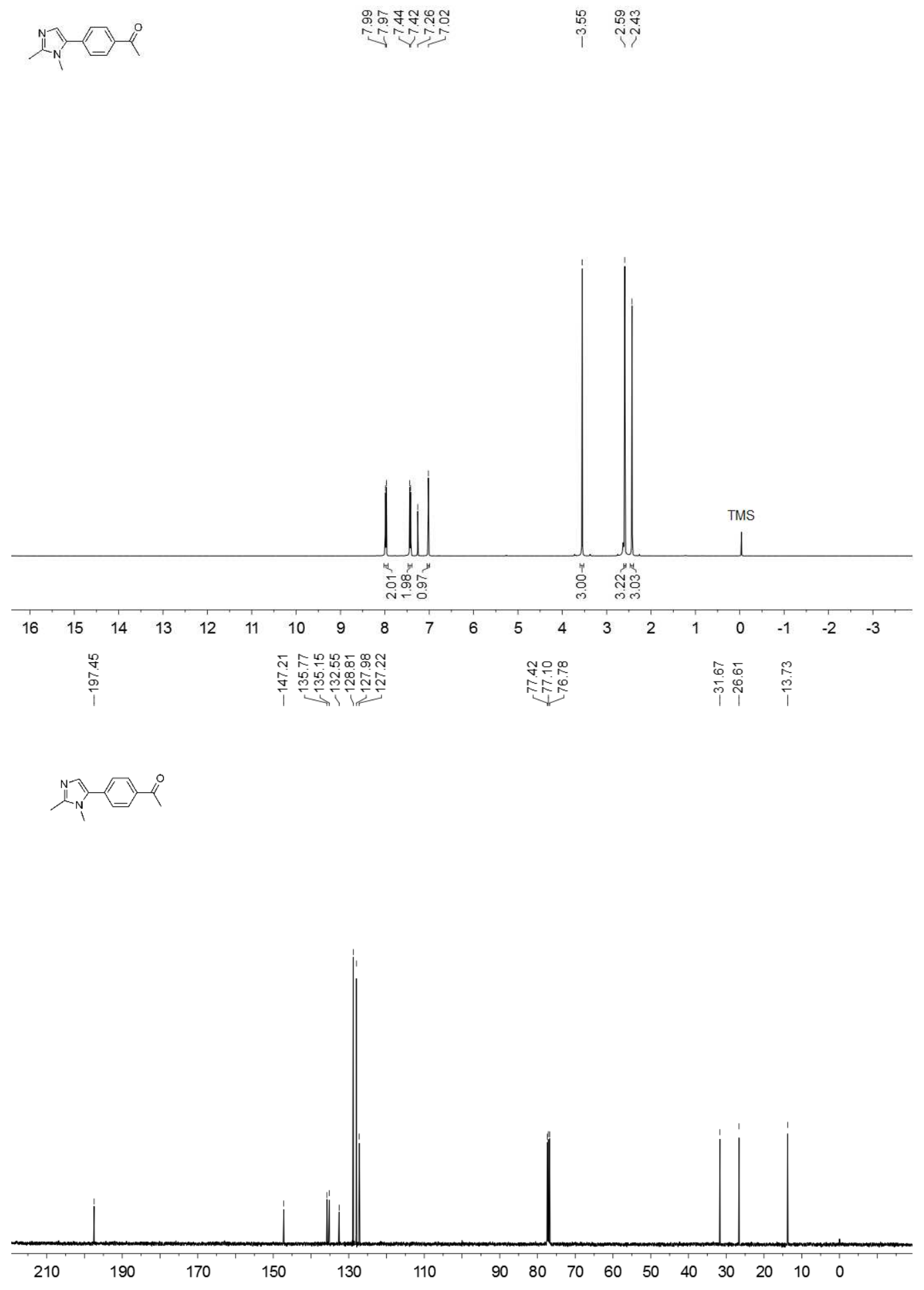
$\begin{array}{lllll}\text { Figure } & \text { S30. } & \text { The } & \text { NMR } & \text { spectrums }\end{array}$ 1,2-dimethyl-5-(4-(trifluoromethyl)phenyl)-1H-imidazole (9bg)
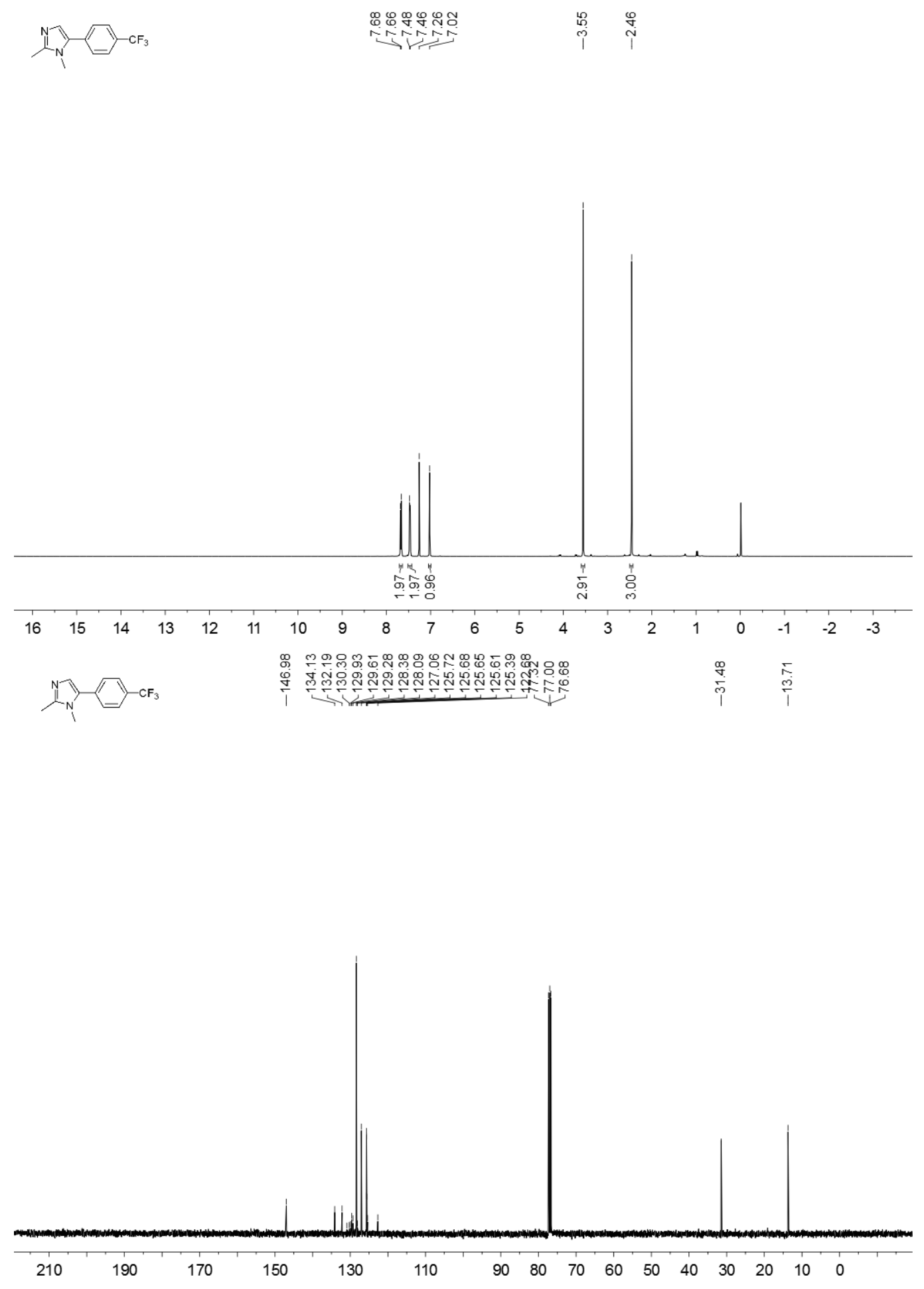
Figure S31. The NMR spectrums of 5-(4-fluorophenyl)-1,2-dimethyl-1H-imidazole (9bh)
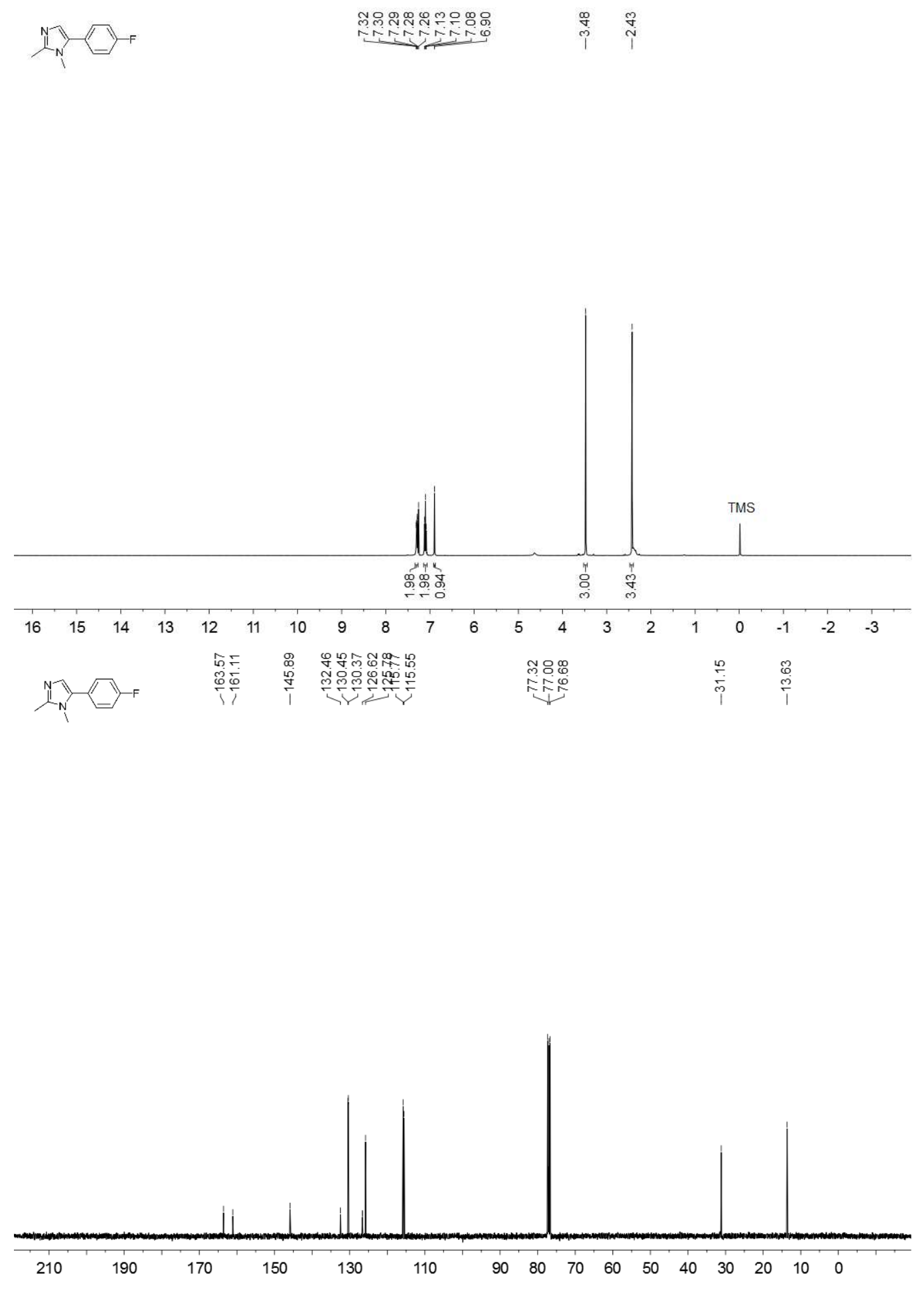
Figure S32. The NMR spectrums of 1,2-dimethyl-5-phenyl-1H-imidazole (9bi)
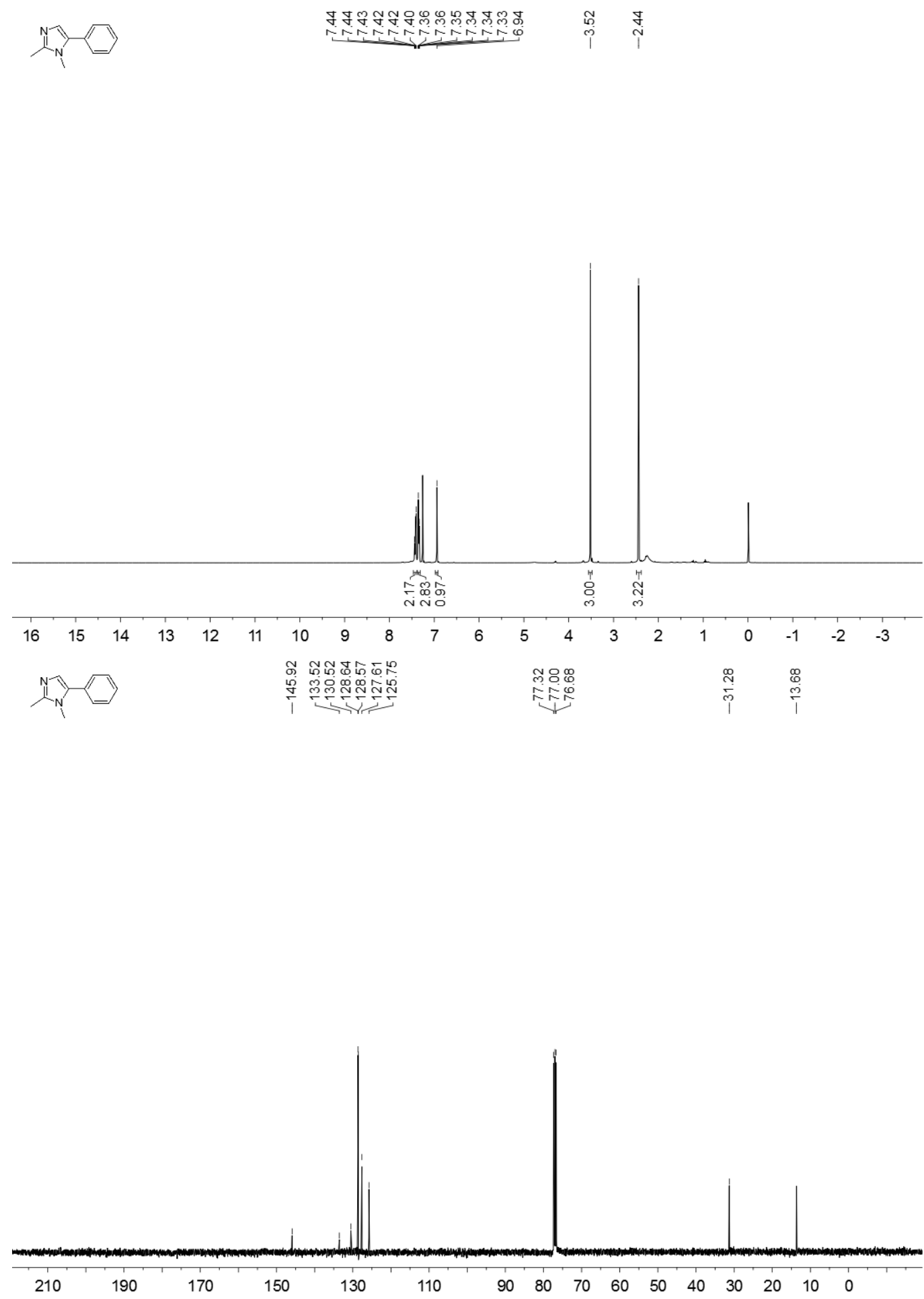
Figure S33. The NMR spectrums of 1,2-dimethyl-5-(naphthalen-1-yl)-1H-imidazole (9bj)
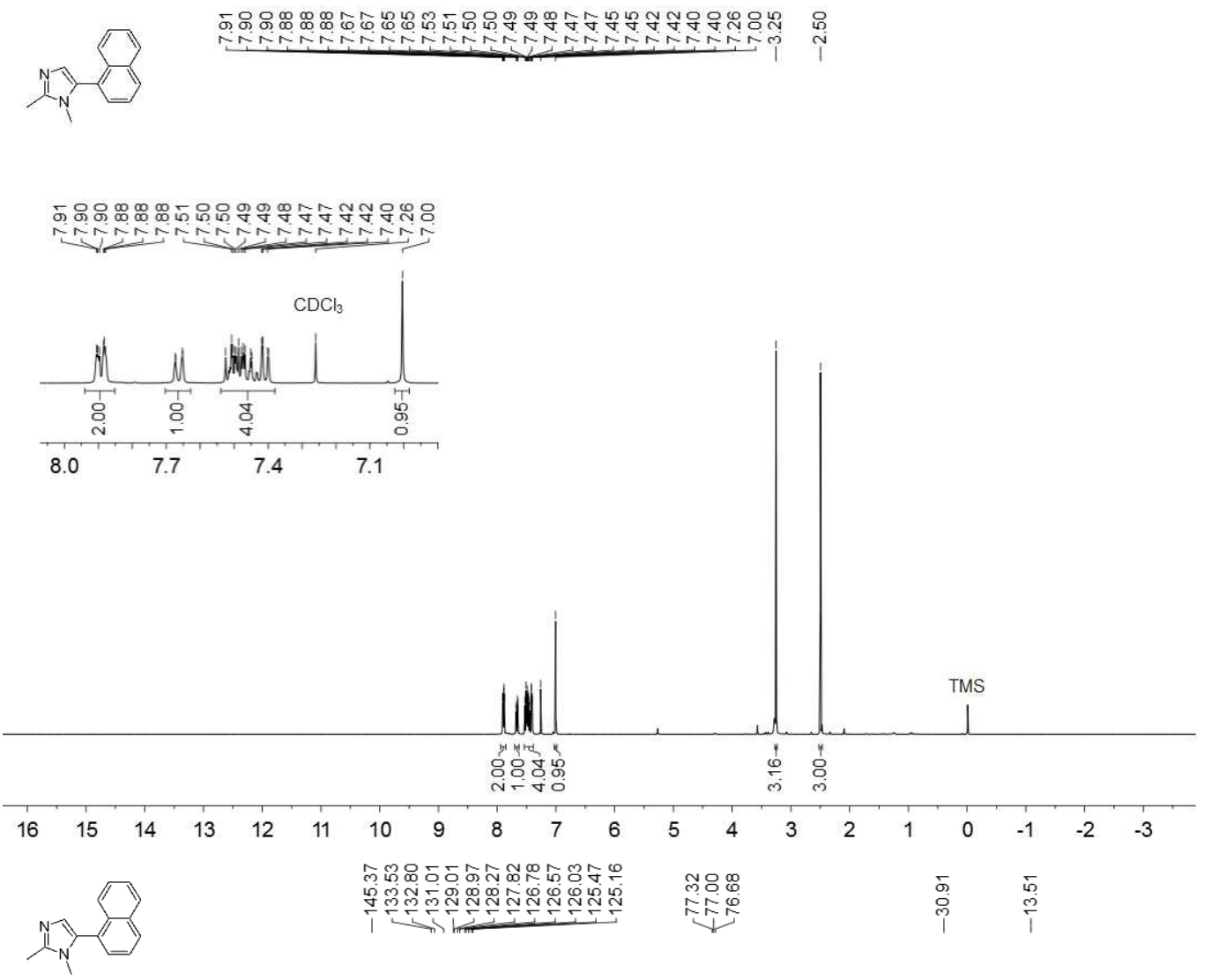

i
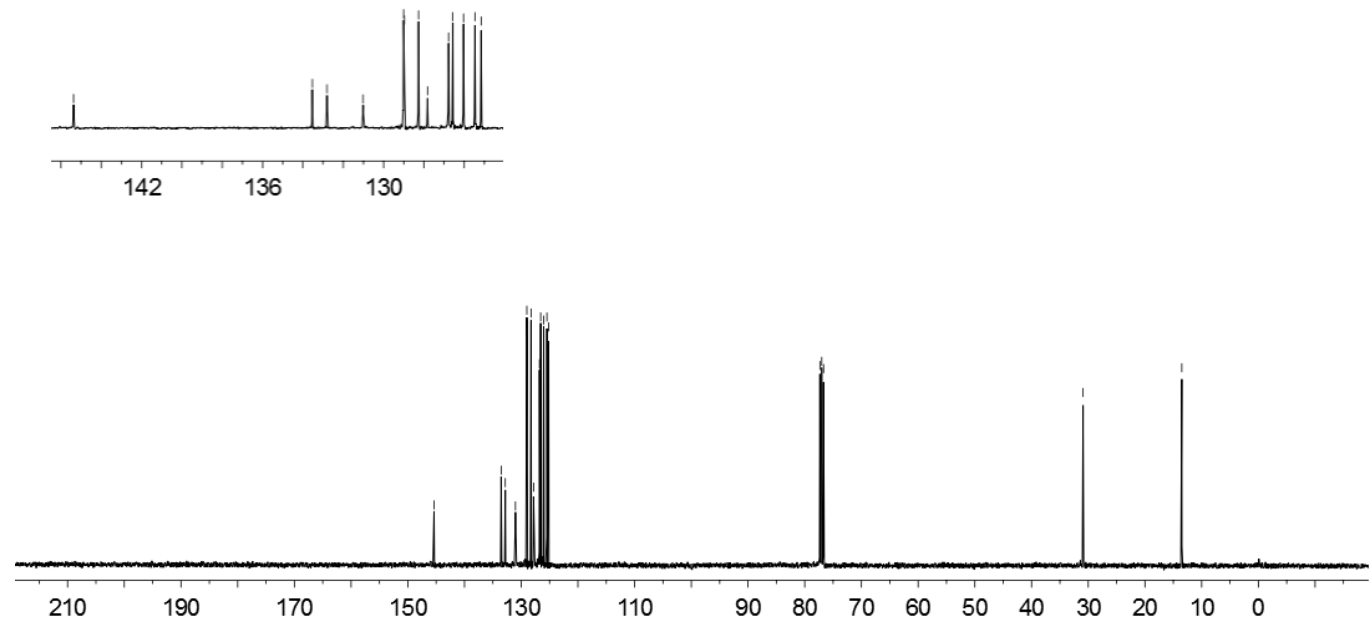
Figure S34. The NMR spectrums of 5-(3-methoxyphenyl)-1,2-dimethyl-1H-imidazole (9bk)
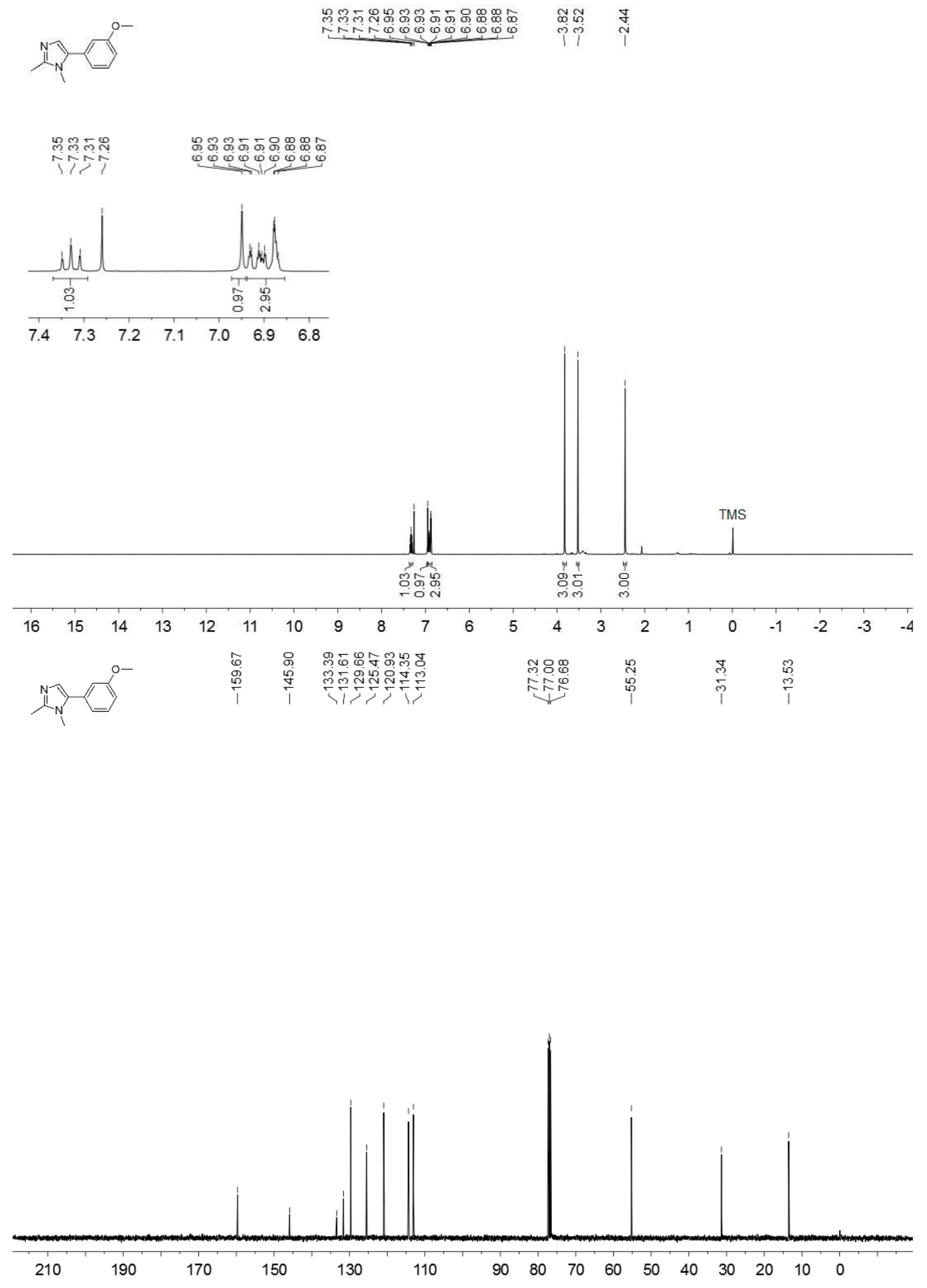
Figure S35. The NMR spectrums of 4-(1,2-dimethyl-1H-imidazol-5-yl)isoquinoline (9bl)
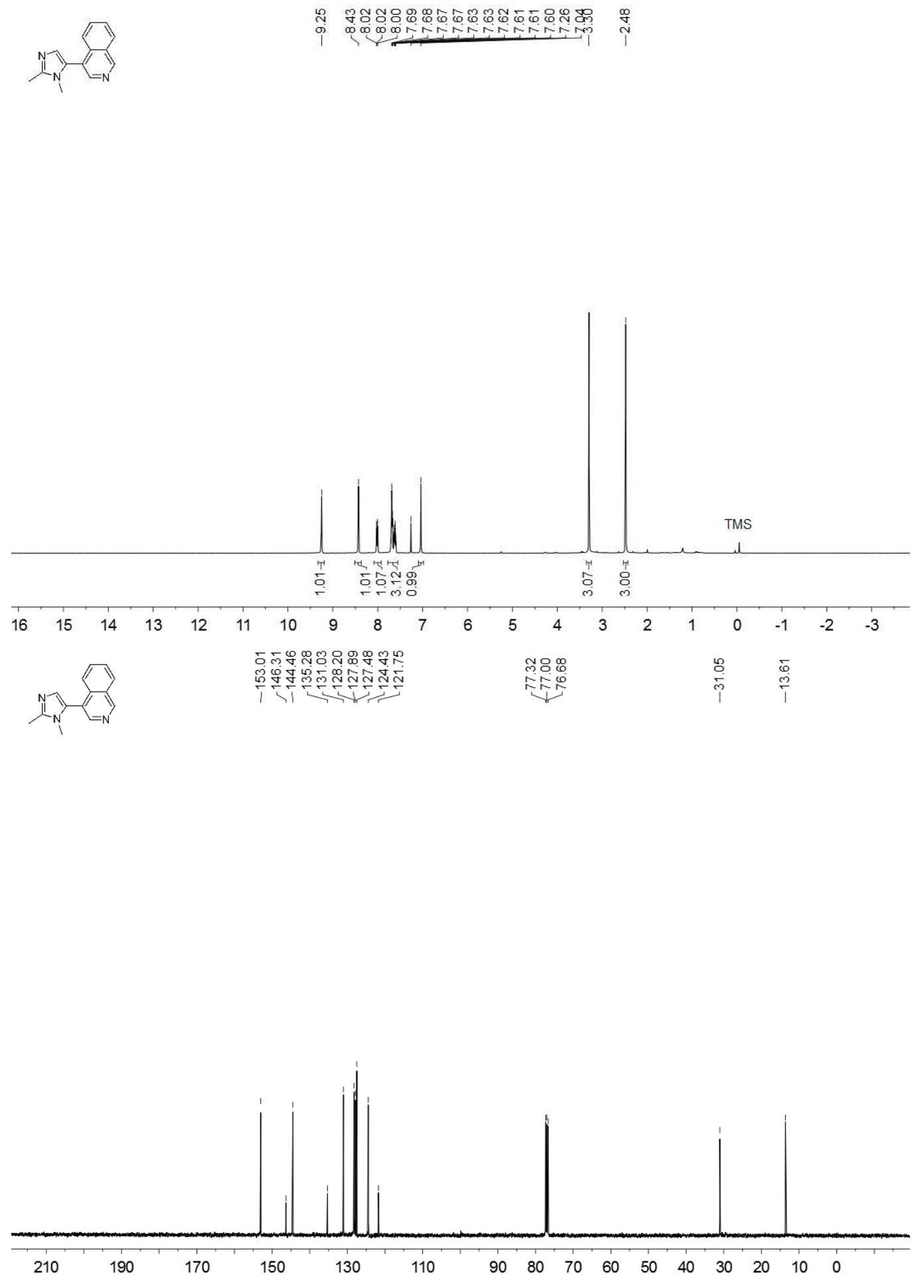